\title{
Investigation of the Shear Flow Effect and Tip Clearance on a Low Speed Axial Flow Compressor Cascade
}

\author{
Mahesh Varpe and A. M. Pradeep \\ Department of Aerospace Engineering, Indian Institute of Technology Bombay, Powai, Mumbai 400 076, India \\ Correspondence should be addressed to A. M. Pradeep; ampradeep@aero.iitb.ac.in
}

Received 30 April 2013; Accepted 31 August 2013

Academic Editor: Enrico Sciubba

Copyright (C) 2013 M. Varpe and A. M. Pradeep. This is an open access article distributed under the Creative Commons Attribution License, which permits unrestricted use, distribution, and reproduction in any medium, provided the original work is properly cited.

\begin{abstract}
This paper explores the effect of inlet shear flow on the tip leakage flow in an axial flow compressor cascade. A flow with a high shear rate is generated in the test section of an open circuit cascade wind tunnel by using a combination of screens with a prescribed solidity. It is observed that a stable shear flow of shear rate 1.33 is possible and has a gradual decay rate until 15 times the height of the shear flow generator downstream. The computational results obtained agree well with the available experimental data on the baseline configuration. The detailed numerical analysis shows that the tip clearance improves the blade loading near the tip through the promotion of favorable incidence by the tip leakage flow. The tip clearance shifts the centre of pressure on the blade surface towards the tip. It, however, has no effect on the distribution of end wall loss and deviation angle along the span up to $60 \%$ from the hub. In the presence of a shear inflow, the end wall effects are considerable. On the other hand, with a shear inflow, the effects of tip leakage flow are observed to be partly suppressed. The shear flow reduces the tip leakage losses substantially in terms of kinetic energy associated with it.
\end{abstract}

\section{Introduction}

In an axial flow compressor, the relative motion between the rotor and the casing necessitates some clearance between them. In the past, limitations of manufacturing technology to produce tight tolerances for the compressor rotor lead to the large tip gap. The undesired excessive tip gap may also develop over a long period of turbomachine operation due to wear and tear of parts. This functional requirement is associated with the undesired loss due to the interaction of the tip leakage flow with the mainstream, passage vortex, boundary layers of the blade, and the end wall near the tip regions. Therefore, the flow through the blade rows becomes threedimensional and complex.

A larger number of theoretical, numerical, and experimental studies exist on the tip leakage flow related to compressor aerodynamics. The formation of tip leakage vortex and its downstream advancement while interacting with the mainstream flow and the surface boundary layers becomes the flow features of the tip leakage flow. Rains [1] and Chen et al. [2] described the formation of the tip leakage vortex under the influence of the pressure gradient across the tip gap bound by the blade surfaces and its interaction with the mainstream. Storer and Cumpsty [3] studied the tip leakage flow in a compressor cascade by both experimental and numerical investigation and found that the tip leakage vortex formed at the maximum loading point and moved downstream as the tip gap increased. Khalid et al. [4] studied the effect of tip clearance on end wall blockage in an axial compressor using a simple model similar to the definition of boundary layer displacement thickness. The mechanism of the blockage was pursued as the interaction of the tip leakage flow with the mainstream flow. Blockage increased by $5 \%$ for double the increase in the tip clearance. With tight tip clearances, the end wall effect becomes more influential than the tip leakage flow in the loss mechanism. Denton [5] proposed a model for predicting the losses in terms of the entropy generation. He stated that most of the entropy generation occurs during mixing of the tip leakage flow with the mainstream flow. The tip leakage vortex exerts little influence on the development 
of the boundary layer on the suction surface of the blade. Further, the structure of the tip leakage vortex does not affect the entropy generation. PIV measurements by Soranna et al. [6], in the tip region of the rotor, indicate that the turbulent diffusion is a minor contributor to the evolution of turbulent kinetic energy in the tip region. Zhibo et al. [7] investigated the effect of tip gaps in a low speed axial compressor and found that increase in the tip gap causes delay in the formation of tip leakage vortex and speeds up its pitchwise movement from suction surface to pressure surface of the passage. It was reported that an increase in $1 \%$ of the tip gap almost doubles the blockage effect. Their study concluded that the interaction of tip leakage vortex with the free stream flow inhibits the blockage effect. Williams et al. [8] conducted large tip clearance study on a low staggered compressor cascade and reported that the tip leakage loss unaffected by the tip clearance greater than $4 \%$ of the span and blade loading in the tip region was improved for tip gap greater than $2 \%$ of the span. Tip leakage vortex does not show tendency of pitchwise movement and was found to be the cause of improved blade loading. You et al. [9] studied the effect of tip gap using LES and found that magnitudes of vorticity and turbulent kinetic energy in the tip leakage vortex are reduced as the tip gap size decreases. The optimum rise in static pressure across the cascade was observed at the smallest tip clearance. The study concluded that the fundamental features of the tip clearance flow were not sensitive to the different tip gap sizes and the smallest tip gap size promotes a static pressure rise in the cascade exit. Roy and Bhatia [10] performed computational studies of tip leakage flow with tip clearance ranging from $1 \%$ to $8 \%$ of the span in a high hub to tip ratio stage. The influence of tip leakage flow along the span reduced in proportion to the tip clearance. The flow features were similar to that by other investigators in the past. Fischer et al. [11] demonstrated an optical measurement technique using doppler global velocimetry to study the features of tip leakage flow in a compressor cascade. The loss region caused by flow separation at the rear suction surface shrunk due to tip leakage flow. It was concluded that the turbulence generated by the tip leakage flow in the near wall region to be the main contributor to the reduction of the blockage effect. The tip leakage flow opposes the secondary flow and aids in reduction of the secondary flow losses, so that the overall loss is minimized [12].

The inflow unsteadiness also influences the tip leakage vortex either directly or indirectly largely in response to tip clearance height [13]. Lakshminarayana et al. [14] pointed out that there are substantial differences in the structure of tip clearance flow as observed in cascades and rotors of axial compressor. Like in a rotor configuration, the leakage jet does not roll up into a vortex and mixes rapidly with mainstream thereby producing considerable turbulence and triggering the flow separation. Apart from tip clearance height, inlet swirl, turbulence intensity, blade loading, Reynolds number, and so forth also influence the tip leakage flow features.

The tip leakage flow does not participate in work transfer by the rotor and therefore is accompanied by energy loss. The tip leakage flow in a stator is influenced by the static pressure difference across the blade surfaces at the tip end, boundary layer on casing, geometry of tip clearance, and the nature of the incoming flow. The cascade experiments are designed to study the effect of individual parameters, like tip gap, angle of incidence, and so forth, on the performance. However, the result obtained would differ with that from the actual turbomachine, since the performance of the actual turbomachine is the result of the superimposition of the effects of such parameters. The attempts of investigation are to model the cascade experimental setup as close as possible to a realistic turbomachine operation. Therefore, it would be interesting to understand the tip leakage flow under the influence of incoming shear flow. This study would involve the design of shear flow generator to produce intended shear flow with minimum turbulence and reduced decay rate. Among the available methods, a combination of screen strips with different solidity was chosen. Cascade was suitably positioned downstream of shear flow generator where the decay rate has minimal influence on the study undertaken.

\section{Design of the Shear Flow Generator}

The end wall effects could be amplified with substantial inlet vorticity for a chosen optimum camber angle of the blade. A method of generating maximum shear with negligible decay downstream has to be selected. To generate a shear flow, various methods are available with their benefits and limitations well documented [15-23]. The turbulence intensity generated by the shear flow generator would suppress the role of secondary flows. Therefore, it was decided to use screen as a shear flow generator. The design approach was similar to that applied to the plane of rods by Owen and Zienkiewicz [15]. Initially, using (1), attempts were made to design a wire grid of SWG $30(0.3 \mathrm{~mm})$ :

$$
\frac{\sigma^{2}}{(1-\sigma)^{2}}=K_{0}\left[1-\frac{2 h \lambda}{U}\left\{\frac{1}{K_{0}}+\frac{1}{1+a}\right\}\left\{\frac{y}{h}-\frac{1}{2}\right\}\right],
$$

where $K_{0}=\left(P_{1}-P_{2}\right) /(1 / 2) \rho U^{2}, a=1.1 / \sqrt{\left(1+K_{0}\right)}$, and $\lambda=$ $\partial U / \partial y$. Design values are $K_{0}=12, h \lambda / U=1.18$.

According to the design, it was difficult to find the screens with varying porosity. The specific shaped screen with constant porosity or multiple screens with different gauges were cumbersome and difficult to work with. Therefore, based on an empirical approach, the strips of selected wire gauzes laid side by side and positioned symmetrical to midspan were adopted. From the distribution of the solidity obtained from the design, the solidity of each strip was chosen approximately equal to the mean solidity corresponding to the span range covered by the strip. The screens with different solidity and the same wire diameter were not commercially available. Therefore, with trial and error attempts, a nearly uniform shear flow along the span with shear rate of 1.33 was obtained using the combination of screen strips of SC1:SC2:SC3: $3: 1: 1$. The specification of the wire mesh and configurations of three screens adopted in this study are shown in Figure 1. 


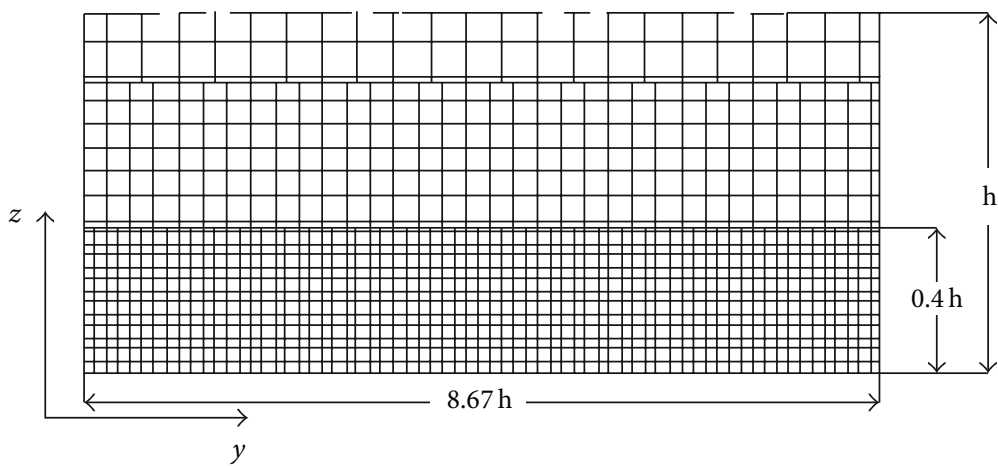

\begin{tabular}{|c|c|c|}
\hline Screen & $\begin{array}{c}\text { Wire diameter } \\
(\mathrm{mm})\end{array}$ & Solidity \\
\hline SC1 & 0.1 & 0.38 \\
\hline SC2 & 0.16 & 0.34 \\
\hline SC3 & 0.28 & 0.22 \\
\hline
\end{tabular}

FIGURE 1: Details of shear flow generator consisting of strips of screens.

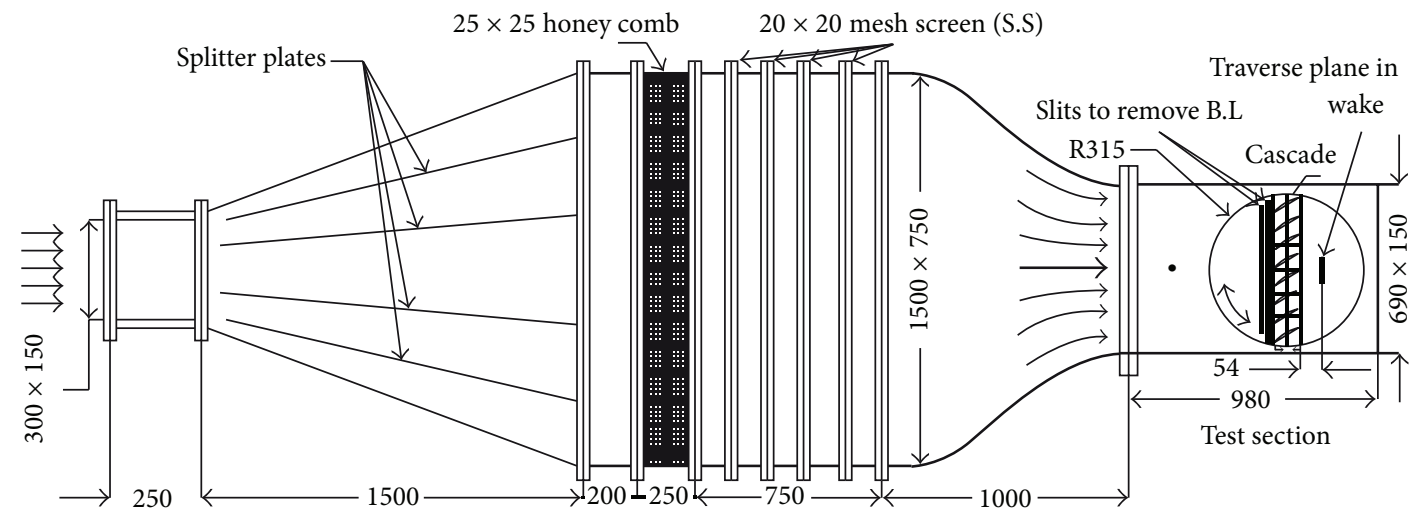

FIgURE 2: Schematic diagram of open circuit cascade wind tunnel.

\section{Experimental Setup}

The present work was a part of the study on mechanisms to control end wall losses. Unlike a turbine blade, a compressor blade has a comparatively low camber. Subsequently, at small incidence angle or lower blade loading, the resulting secondary flows would be weak. It becomes difficult to evaluate the effectiveness of the mechanisms to control the losses. The secondary flow effect could be amplified by increasing the incidence angle for low cambered airfoils. It was known from the literature that the secondary flow effects limit the performance especially at higher blade loading or off design conditions. Therefore, an incidence of $10^{\circ}$ was chosen. Further, the tip leakage flow counteracts the secondary flow and the optimum tip clearance would depend on the magnitude of the prevailing secondary flow. Hence, the work presented in this paper was pursued to study the interaction of the tip leakage flow with the elevated secondary flows.

The experimental data for the baseline configuration was acquired to validate the CFD results. The experimental investigations were carried out in a low speed, open circuit, and cascade wind tunnel, shown in Figure 2. A $55 \mathrm{~kW}$ centrifugal blower was used to provide uniform flow at the inlet of test section. The test section is a rectangular duct of crosssection $690 \mathrm{~mm} \times 150 \mathrm{~mm}$ to accommodate eight C4 blades. The cascade arrangement along with the shear flow generator in the test section is shown in Figure 3(a).
TABLE 1: Specification of the cascade.

\begin{tabular}{lc}
\hline Chord length $(C)$ & $115 \mathrm{~mm}$ \\
Stagger $(\gamma)$ & $30^{\circ}$ \\
Solidity $(C / s)$ & 1.51 \\
Aspect ratio $(\mathrm{H} / \mathrm{C})$ & 1.3 \\
Blade inlet angle $\left(\beta_{1}^{\prime}\right)$ & $46^{\circ}$ \\
Camber angle & $37^{\circ}$ \\
Re & $2.1 \times 10^{5}$ \\
Inlet flow angle $\left(\alpha_{1}\right)$ & $56^{\circ}$ \\
\hline
\end{tabular}

The cascade parameters are summarized in Table 1 . The tests were conducted at a Reynolds number of $2.1 \times 10^{5}$, based on the blade chord. A variation in the inlet mean velocity of about $0.5 \%$ was found at midspan along the pitchwise direction.

3.1. Instrumentation and Data Reduction. To acquire detailed information of the static pressure distribution, a number of pressure ports were provided on the blade surface. Sixteen pressure taps of $2 \mathrm{~mm}$ diameter running along the span were embedded on the two blades forming the central flow passage. On each surface of interest, 2 rows of ports were internally connected to the pressure taps. The first row of ports was $5 \mathrm{~mm}$ away from the end wall, while the other was located 


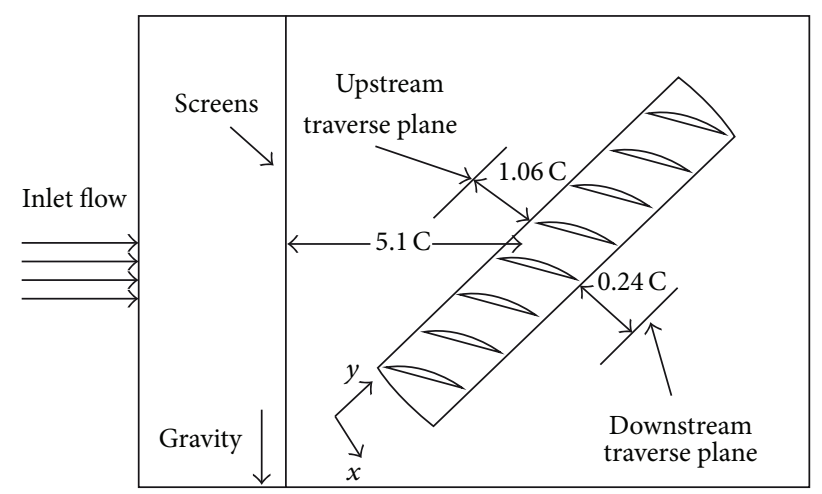

(a)

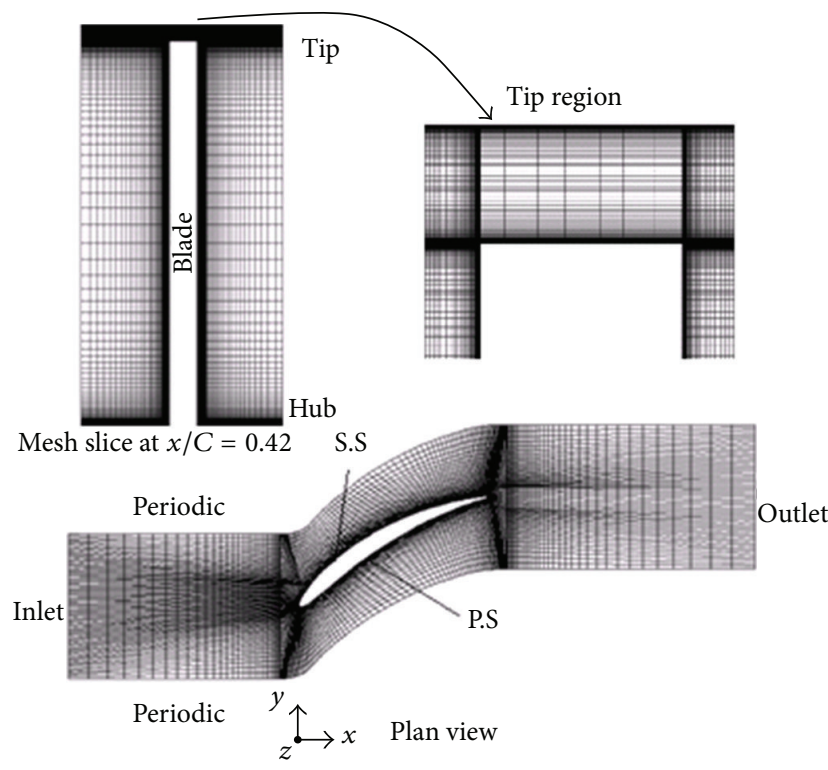

(b)

Figure 3: (a) Plan view of the wind tunnel test section with shear generator. (b) Multiblock structured mesh with the "O" grid around the airfoil and triangular prism mesh in the tip region only.

at the midspan. The static pressures of each row, by masking other row, were picked up by a 16 channel pressure transducer (from M/s Scanivalve Corp., USA). The raw data was acquired and processed using the DSALINK software provided along with the Scanivalve. At the inlet, located one chord ahead of the leading edge of the cascade, a 7-hole probe of $1.6 \mathrm{~mm}$ dia. (from M/s Aeroprobe Inc., USA) picked up the velocity and the static pressure. The estimated uncertainty of the pressure measurements on the blade surface was about $1 \%$.

The end wall loss was obtained by subtracting the total pressure loss at a location from that at the mid span of the no tip gap configuration. The pitch averaged outlet flow angle at the midspan of the no tip gap configuration was taken as the reference outlet flow angle for determining the secondary flow vectors. The secondary flow vectors are nondimensionalised with the inlet mean velocity.

\section{Computational Study}

To get a better insight of the effect of the inlet shear flow and the tip clearance on the cascade, a detailed numerical analysis using ANSYS Fluent was carried out. The experimentally measured velocity profile was prescribed at the inlet of the domain. In the case of inlet shear flow, the velocity components measured downstream of shear flow generator were used as inlet boundary condition. An outflow boundary condition was used at the outlet. The periodic condition was specified for periodic boundaries. A multiblock structured mesh with "O" grid attached to the airfoil was generated using the grid generator, GAMBIT, and is shown in the Figure 3(b). A mesh of triangular prism cells was used in the tip gap region only. The total pressure loss in the wake was considered as a parameter of interest for grid insensitivity analysis. Apart from grid size, it was observed that $y+$ also affects the CFD results. Based on this study, a mesh size of about 2.1 million was finalized for the no tip gap configuration. This mesh was refined near the walls to capture the viscous effects adequately. The corresponding $y+$ value was kept nearly one. The mesh size increased with the tip clearance and was 3.2 million for $4 \%$ tip clearance. For the $4 \%$ tip clearance case, there were 75 elements along the span in the tip gap region. In the other configurations of tip clearance, the corresponding mesh elements were relatively less with $y+$ value maintained near to one. To capture the flow separation on the suction surface, if any, other vortical interactions nearly 109 nodes on suction side of blade were used, whereas pressure side had 76 nodes. The steady-state flow solution was achieved using $\kappa-\omega$ SST turbulence model. To yield better accuracy by reducing numerical diffusion, a third order MUSCL discretization was employed. SIMPLEC method was used for pressure velocity coupling. Default settings for solution controls were used and no acceleration techniques were applied. For convergence of the scaled residuals to $10^{-6}$ for all the equations, approximately 8000 iterations were required. It was observed that the mesh quality also affects the rate of convergence apart from the complex flow dynamics.

4.1. Validation of the CFD Results with Experimental Data. A comparison of CFD and experiment with uniform flow at the inlet for the incidence of $10^{\circ}$, in terms of static pressure coefficients on the $\mathrm{C} 4$ blade surface, was performed. The static pressure coefficients of the blade surface at the midspan and close to the end wall are as shown in Figure 4. At the midspan, the CFD results agree closely with the pressure distribution from the experiments. It obviously indicates that numerical modeling with the prescribed boundary conditions is reliable. Near the end wall, CFD model's prediction of the pressure distribution on the blade surface, in case of uniform flow, is poor. This may be due to CFD model's limitation to account for three-dimensional separations induced by the secondary flow and boundary layers of the blade and the end wall. The blades were made from the epoxy based translucent material using rapid prototyping process. Since the thickness of the blade was $8 \%$ of the chord and the trailing edge thickness 

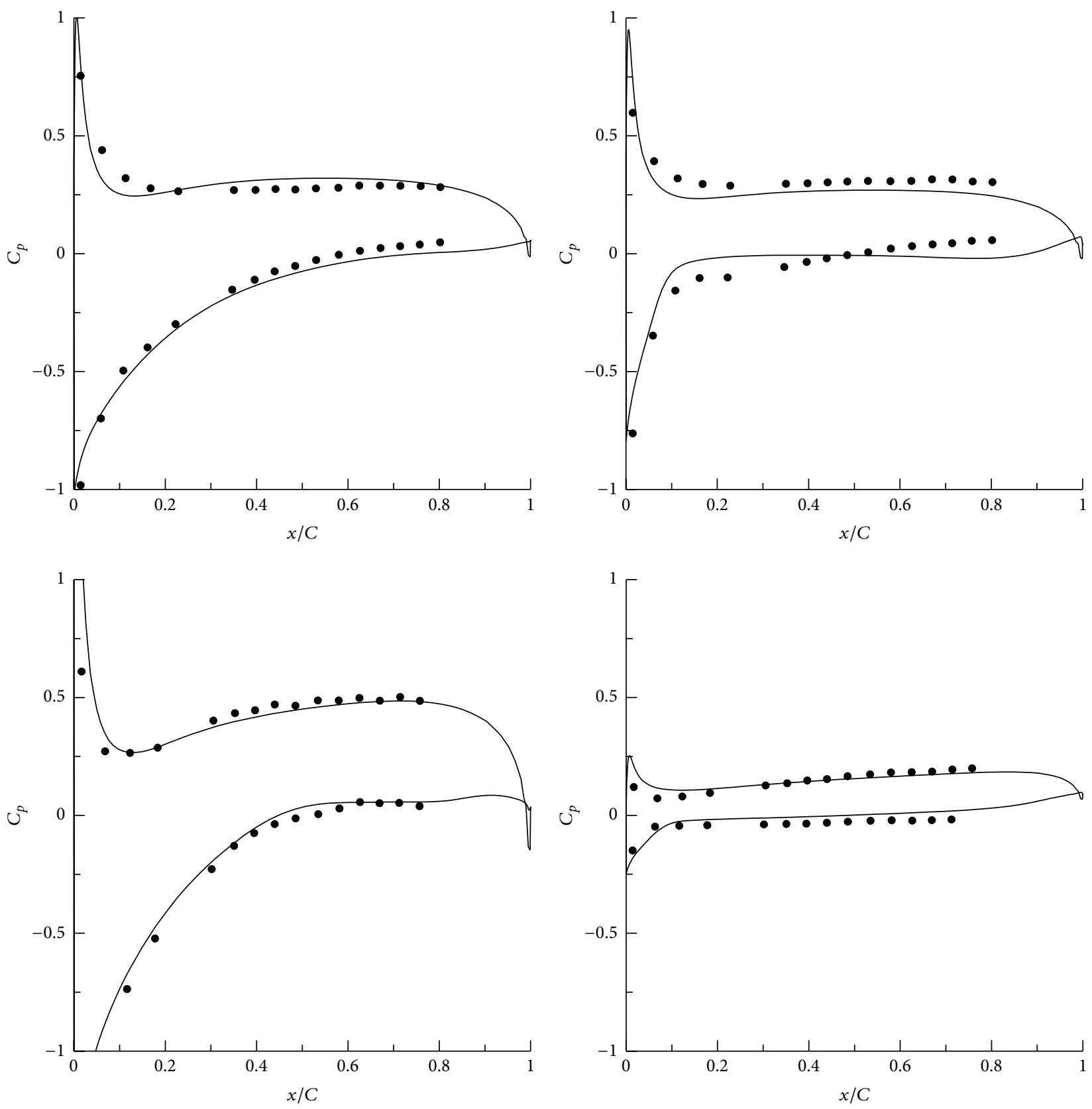

- Experiment

- Experiment - CFD

(a)

(b)

Figure 4: Comparison of $C_{p}$ on C4 blade surface between experiment, and CFD at $i=10^{\circ}$, (a) $z / H=50 \%$, midspan and (b) $z / H=0.03$, near the end wall.

of the blade was about $0.87 \%$ of the chord, it was difficult to have pressure taps of $2 \mathrm{~mm}$ and the corresponding surface pressure ports. Therefore, the experimental values acquired were limited up to $80 \%$ of chord, in the plots of static pressure coefficient. The blade loading near the wall is severely affected by the incoming shear flow and the difference between the experiment and CFD is relatively small.

\section{Results and Discussion}

Most of the previous investigations on the tip clearance and its characteristic flows indicate that tip gap greater than $4 \%$ of the span has little or negligible effect on the performance. Therefore, the present study focuses on tip gaps of $0.5 \%, 1 \%$, $2 \%$, and $4 \%$ of the span that correspond to $0.65 \% \mathrm{C}, 81.3 \% \mathrm{C}$, 
$2.61 \% \mathrm{C}$, and $5.22 \% \mathrm{C}$. The tip clearance in percentage of the span would be referred from this point onward for discussion in the rest of the paper. The performance is studied for both uniform flow and a prescribed shear inflow in the presence of tip gap.

5.1. Shear Profile Decay. To achieve maximum shear from the available flow energy at the inlet, the velocity near the wall should be as minimum as possible. The flow resistance offered by the screen located near the wall was inadequate and therefore with trial and error attempts, three strips of SC1 and single strip for others were found to generate nearly uniform flow. The resulting velocity profiles generated downstream of the shear generator at different axial locations are shown in Figure 5. As the flow proceeds downstream of the shear generator, the peak axial velocity is reduced by the shear stress produced from the flow resistance along the span of the shear generator. The instability of the shear stress at the spanwise boundaries of the zones covered by the respective screen strips occurs due to the sudden jump in the solidity or flow resistance. This increases the turbulence relative to the rest of the span. Further, the turbulence is produced by the small-scale shear between the consecutive jets and wakes of the screen wires, which increases the interaction between the near wall flow region and the free stream flow. This enhances the mean velocity in the region near the end wall, as can be seen in Figure 5(a). The overall effect is the reduction of the shear rate in the downstream regions. Grid generated turbulence decays downstream under the influence of the shear stresses. Thus, the velocity field has a nature of self-preserving development of a natural turbulent flow.

Among the lateral components, " $z$ " velocity variation along the span of the grid is higher as seen in Figure 5(c). This is because the fluid under shear, owing to its reduced velocity in the $x$-direction, readily acquires a motion in the $z$ direction in response to the pressure gradient than the fastermoving fluid in the mainstream. Once a lateral flow is well established in the boundary layers, a compensating flow must appear in the mainstream in order to preserve continuity, which would occur under stable flow conditions. In general, the velocity profile decays very slowly in the downstream up to $15.13 \mathrm{~h}$, covering the axial length of the cascade test section.

5.2. $C_{p}$ on Blade Surface. The features of tip leakage flow in presence of uniform flow at the inlet are well understood in the past and have been reported by several investigators. The present study explores the effect of inlet disturbance in terms of shear flow on the tip leakage flow.

5.2.1. Tip End. The static pressure coefficient on the blade surface near the tip is shown in Figure 6. With no tip clearance and uniform flow at $i=10^{\circ}$, it is seen that blade loading is severely affected at the tip from $93 \%$ span and is nearly constant along the chord from $10 \% \mathrm{C}$ onwards. This shows that the end wall effect is substantial that reduces blade loading, to which the suction surface side is a major contributor. In the presence of tip clearance, however, small it may be, the $C_{p}$ distribution on the blade near the tip region is considerably improved. This improvement can be attributed to favorable change in local incidence and removal of the corner vortex (for no tip gap) near the tip by the leakage flow. The point of maximum loading at the tip end moves downstream along the chord as the tip clearance is increased. This determines the location of the intense leakage flux along the chord. It is also evident that the flow separation at the tip of the suction surface end extends along the chord with increase in the tip clearance. At a large tip clearance of $4 \%$, flow separation occurs over $50 \% \mathrm{C}$ from the leading edge. Therefore, the blade loading is locally affected. This information could be used in implementing tip leakage control mechanisms.

When shear flow is introduced into the cascade, the blade characteristics at the tip end are quite different. The blade loading near the tip region is reduced compared to the uniform flow case and is nearly unaffected by small tip clearances up to $2 \%$. At $4 \%$ tip clearance, the flow separation near the tip end extends up to $30 \% \mathrm{C}$ that is lower compared to the uniform inflow case. The difference in the $C_{p}$ characteristics at the tip end could be attributed to the low energy fluid that exists in the near wall region so that the resulting momentum transfer is reduced relative to the uniform flow. This leads to lower $C_{p}$ on the blade surfaces near the tip region. The tip leakage flow in proportion to the developed pressure gradient across the blade has limited influence on the flow separation along the chord at the tip end. Further in contrast to uniform inflow, the magnitude of $C_{p}$ near the leading edge is bound to exceed unity as a large portion of the flow energy is concentrated towards the midspan region. Hence, the local static pressure, equivalent to local total pressure (at the stagnation point), will be greater than the average inlet dynamic pressure and according to the expression of coefficient of static pressure, values may exceed one.

In both the cases, even at high incidence angles of $10^{\circ}$, it is observed that at the mid span after $x_{n}=0.5$, the flow does not separate on the suction surface. However, it does not contribute to the pressure recovery. This may be attributed to the characteristics of C4 profile chosen for this study. The prevailing losses as discussed in subsequent sections would have major contributions from the tip clearance and the end wall effects.

5.2.2. Blade Pressure Surface. The tip leakage flow, though it occurs locally, affects the pressure distribution over the entire blade surface and is shown in Figure 7(a). With no tip gap and uniform inflow, the pressure contours are concentrated near the leading edge of the pressure surface, indicating rapid acceleration of the flow in the first $5 \%$ of the chord. However, any amount of tip clearance changes the slope of the contour lines, which is an indication of the transfer of higher static pressure towards the end wall side in the first $10 \%$ of the chord. The point of static pressure recovery "a", from Figure 7(a), due to diffusion at the tip end shifts along the chord in the downstream direction. This thereby reduces the static pressure recovery due to diffusion. The zone of lower pressure " $b$ ", at the tip, created due to the leakage flow is negligible and appears for tip clearance greater than $1 \% \mathrm{C}$. The overall effect of the tip clearance is to shift the centre of pressure away from the midspan and towards the tip region. 


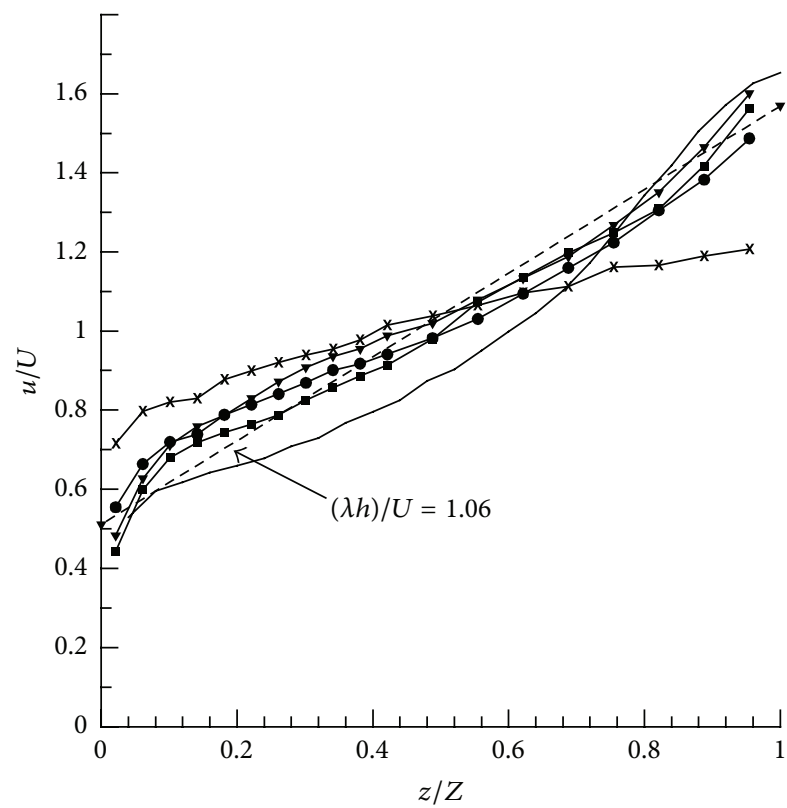

(a)

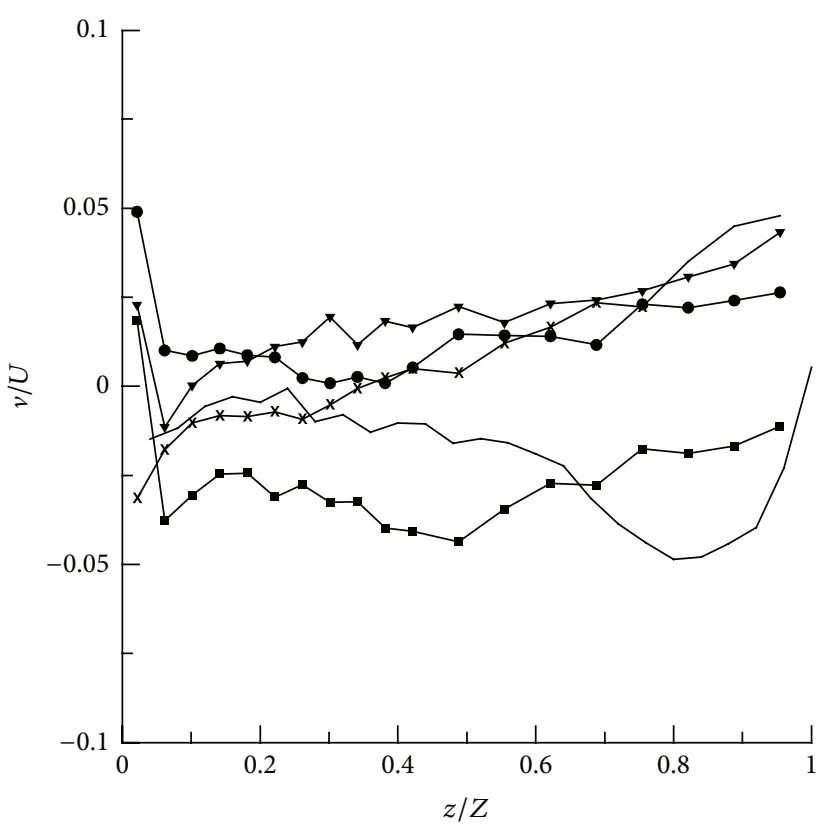

(b)

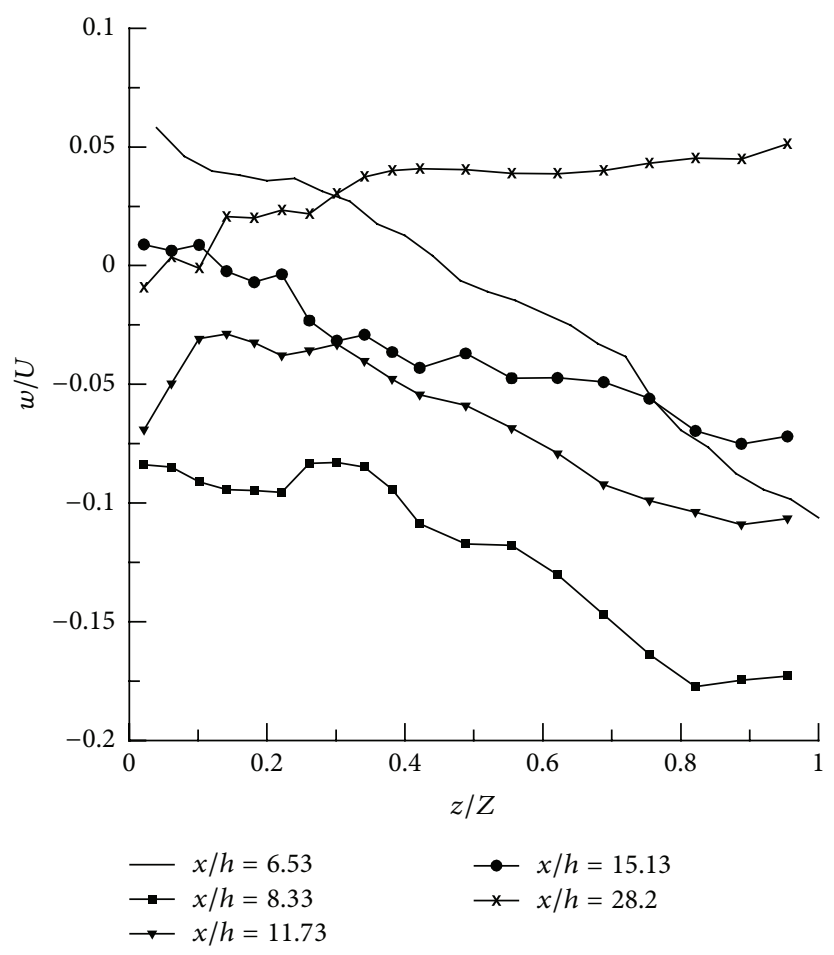

(c)

FIGURE 5: Velocity profile decay of shear flow, generated by screen.

Under the influence of shear flow, the zone of low pressure " $b$ ", near the tip, enlarges until $1 \%$ of tip clearance and then stretches along the chord for higher tip clearance. Similar behavior is observed in the low pressure region " $c$ " near the end wall. This may occur under the influence of the secondary flow driven by the transverse peak pressure gradient that dominates near the end wall region. As the fluid layers near the pressure surface is taken away by the pitchwise pressure gradient, the neighboring fluid layer away from end wall at relatively higher speed occupies the region to satisfy continuity. This therefore causes the low pressure regions " $\mathrm{c}$ " to appear. With gradient in velocity along the span and in 

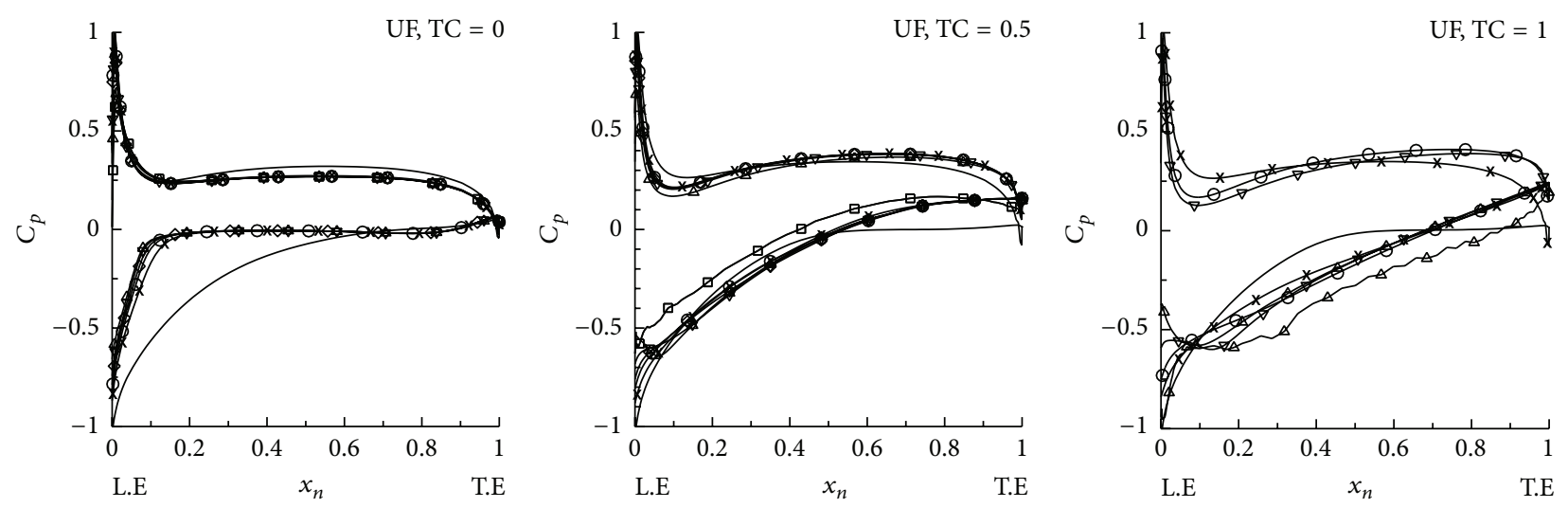

$z / H \%$

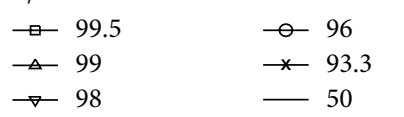

$z / H \%$

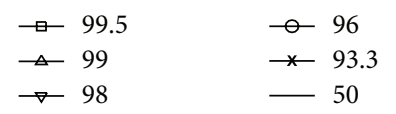

$z / H \%$

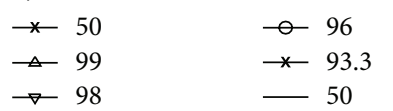

$\diamond 97$

$\checkmark 97$
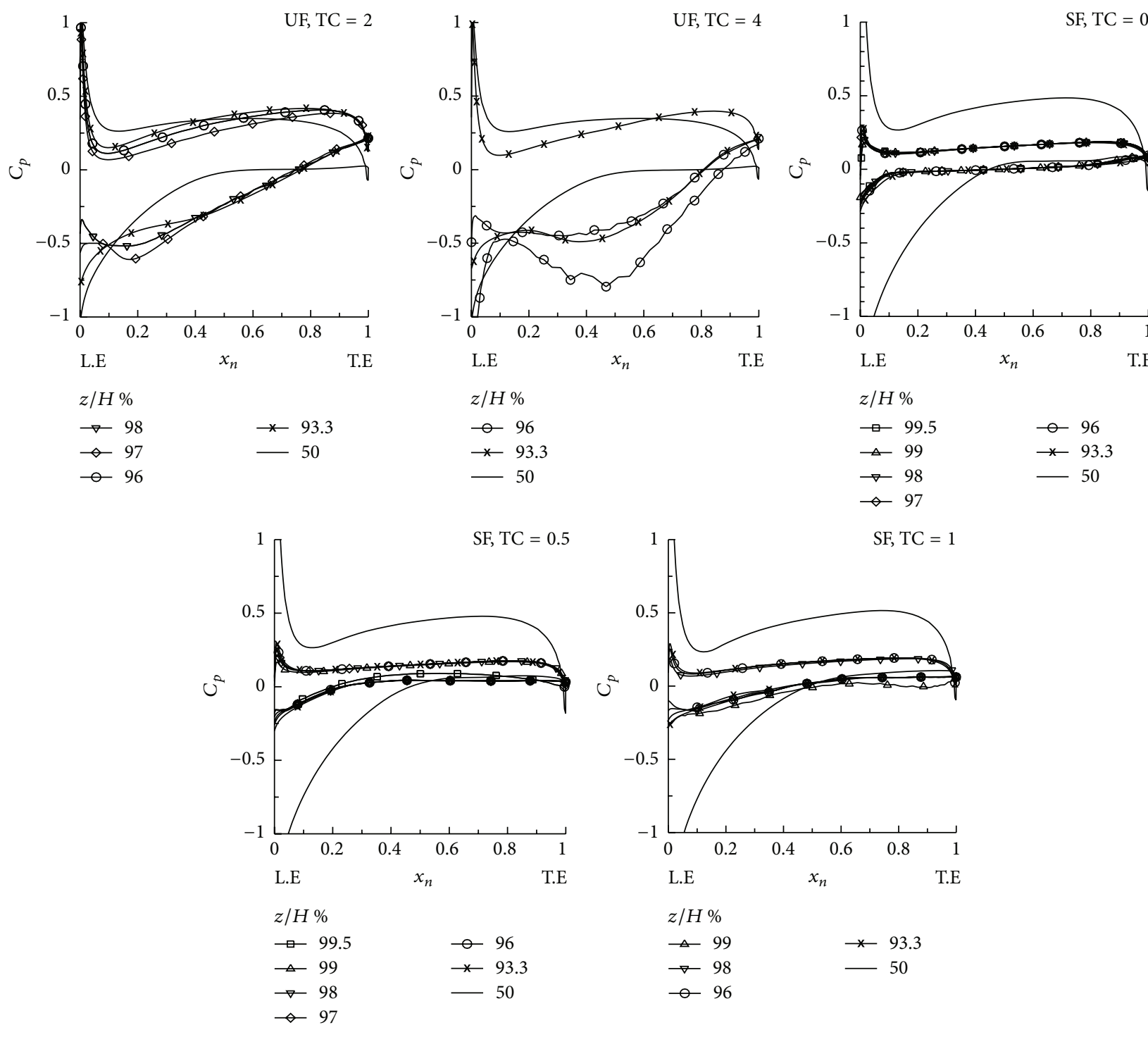

$z / H \%$

$\triangle 99$
$\rightarrow \quad 98$

$\rightarrow-93.3$

- 96

Figure 6: Continued. 


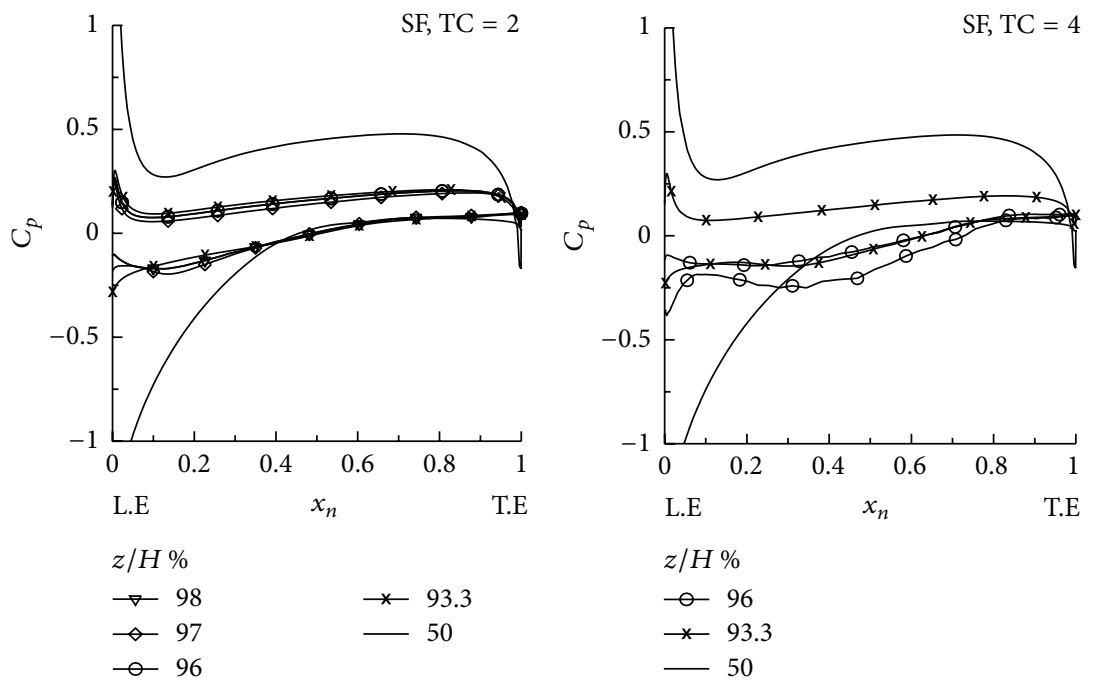

FIGURE 6: $C_{p}$ at tip end with uniform flow and shear flow, for TC $=0$ to 4 .

addition influenced by the tip leakage flow, the flow in the blade passage becomes three dimensionally complex. Consequently, the region " $c$ " behaves in response to region " $b$ ".

5.2.3. Blade Suction Surface. As seen from Figure 7(b), for uniform flow with no tip gap, the contour lines concentrate towards the end wall relative to the midspan. This indicates that the end wall effect is considerable at $10^{\circ}$ incidences. The slope of the contours with respect to span increases with tip clearance indicating that the acceleration and deceleration of the flow is damped and the lower static pressure point is shifted along the chord in the downstream direction. As the tip leakage flux increases with tip clearance, the contours at the tip are stretched along the chord and the region of pressure recovery due to diffusion is pushed further downstream. This makes the blade surface towards the tip side less efficient in terms of work transfer.

On the other hand this does not happen in the presence of inlet shear flow. Due to low momentum fluid near the end wall, the tip leakage flux is reduced owing to the reduced pressure gradient that drives it. Therefore, the contours are affected locally near the tip end only.

5.3. Wake Total Pressure Loss. Tip leakage flow has considerable influence on the distribution of $C_{p_{0}}$ over the blade surface towards the tip end, as seen in Figure 8. With uniform flow at $i=10^{\circ}$ and no tip gap, the total pressure loss is substantial due to the end wall effects. The tip leakage flow energizes the boundary layers of the end wall and the blade surface near the tip region. Further, it counteracts the secondary flow that occurs due to the pitchwise pressure gradient in the blade passage. Therefore, with increased tip clearance, the tip leakage flow is encouraged and this alleviates the total pressure loss near the tip end. However, the loss near the hub is inflated and it appears that some loss is transferred from tip end to the hub end while reducing the overall loss. It can be inferred that, to some extent, the tip leakage flow can be used as a deterrent against the end wall loss. The strength of the loss core near the blade tip diminishes up to $2 \%$ of tip clearance and then rises where it itself contributes to the loss.

The end wall loss is magnified by the incoming shear flow and is quite large for the tip leakage to minimize it. From the contours, it appears that the region of the total pressure loss core towards the tip decreases until $2 \%$ at which tip leakage flux is optimum to counteract the end wall effect. But at $4 \%$ of the tip clearance, since the tip leakage vortex has drifted away from the suction surface, the interaction of the tip leakage flow and the corner stall near the trailing edge of the suction surface is reduced. This results in an additional contribution of loss from the tip leakage flow apart from the stall near the trailing edge of the suction surface. Therefore, the overall loss is increased at higher tip clearances. It can be inferred that if the tip leakage flow has to be used against the end wall loss so that overall loss is minimized, then optimum tip clearance has to be determined by considering the incoming flow distortion or disturbance along with the other parameters.

5.4. Vortices in the Wake. The contours of the vorticity along the reference flow angle in the wake are shown in Figure 9. With uniform flow and no tip gap, the passage $(\mathrm{a}, \mathrm{b})$ and end wall (c) vortices are distinct and are symmetric to the midspan. The vortex marked "a" is the primary passage vortex that induces the secondary passage vortex. Similarly, among the end wall vortices, positive vortex is the corner vortex formed at the junction of blade surface and the end wall, which induces the adjacent vortex. As the tip clearance increases, the passage and end wall vortices towards the tip side disappear. This indicates that the tip leakage flow overcomes the end wall effects near the tip. However, the end wall vortices (c) near the hub side are unaffected, whereas the passage vortices $(\mathrm{a}, \mathrm{b})$ are stretched, in proportion to tip clearance, along the span. The stretching of the passage vortex 

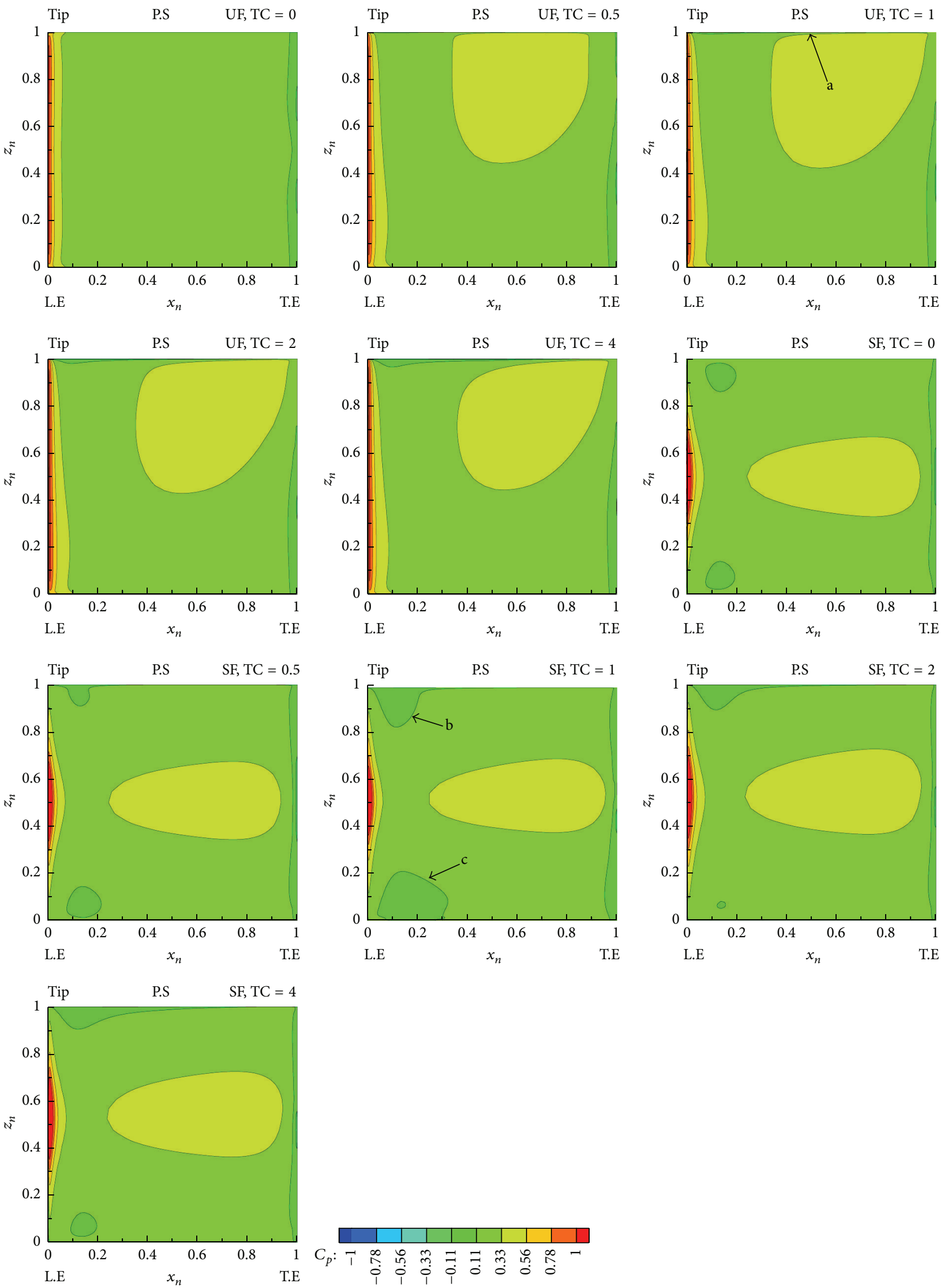

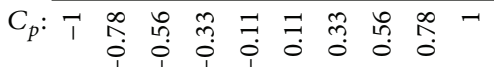

(a)

FIgURe 7: Continued. 

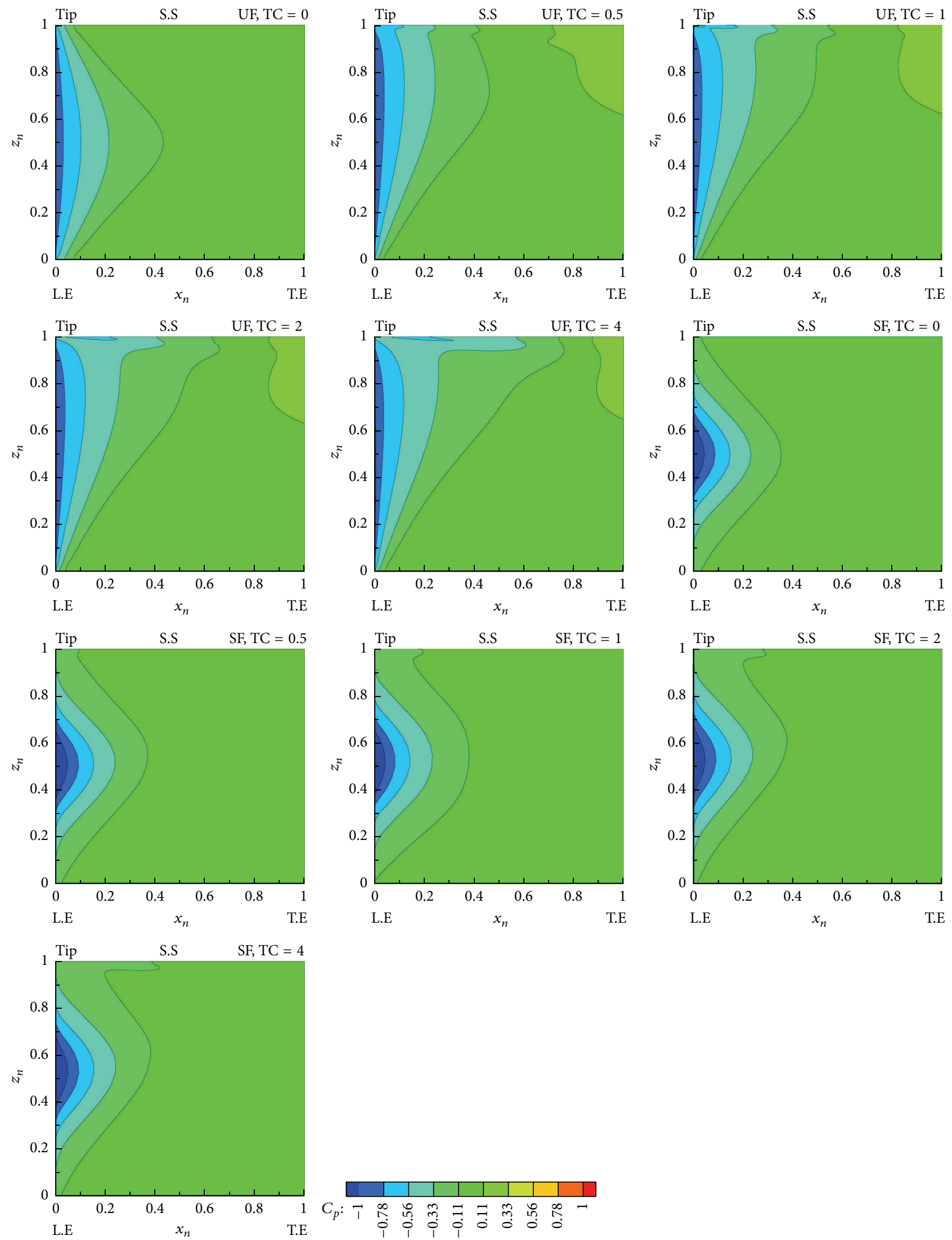

(b)

Figure 7: (a) $C_{p}$ contours on the pressure surface of the blade with UF and SF for TC $=0$ to 4 , (b) $C_{p}$ contours on the suction surface of the blade with UF and SF for TC $=0$ to 4 . 

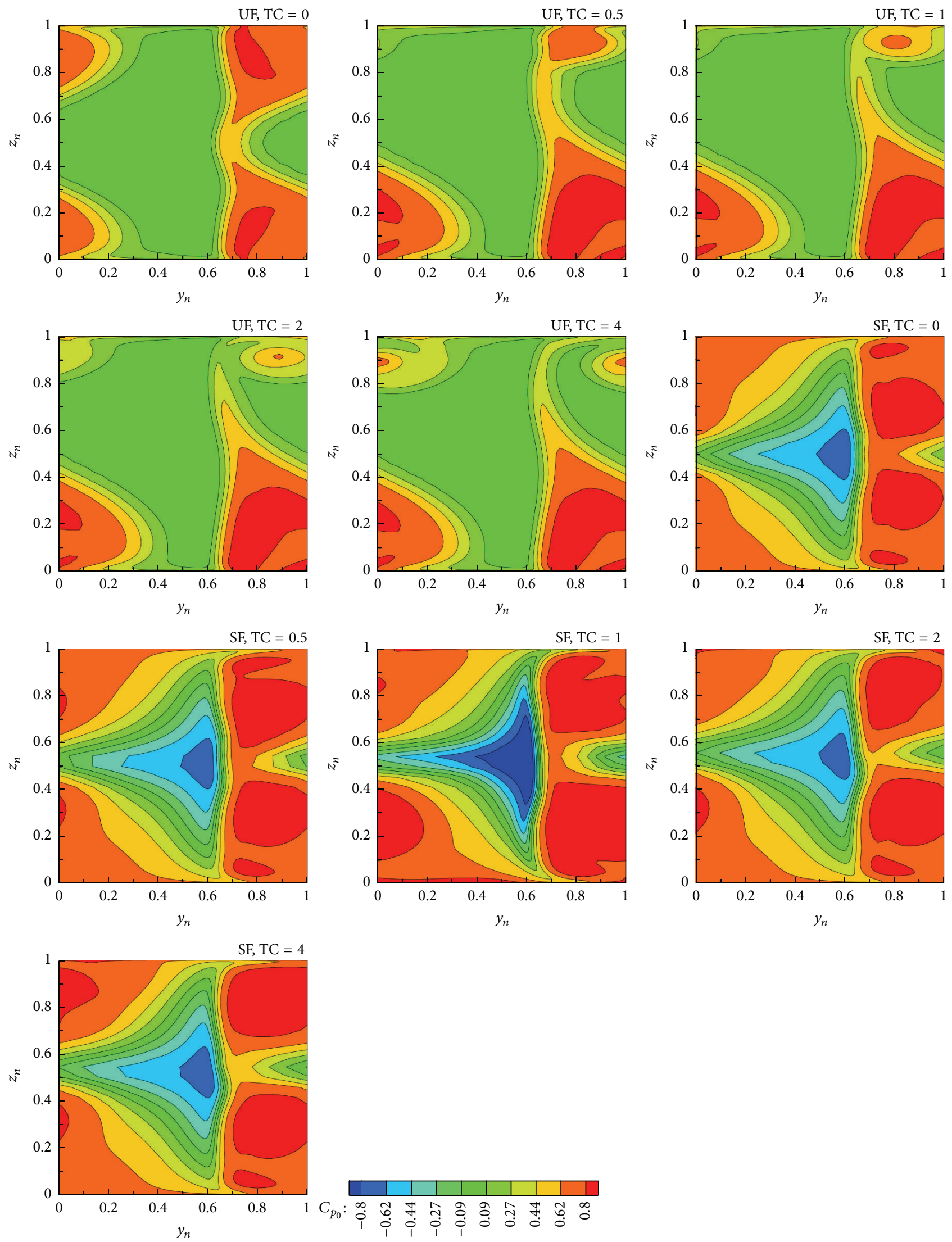

FIGURE 8: $C_{p_{0}}$ contours in the wake with UF and SF for TC $=0$ to 4. 

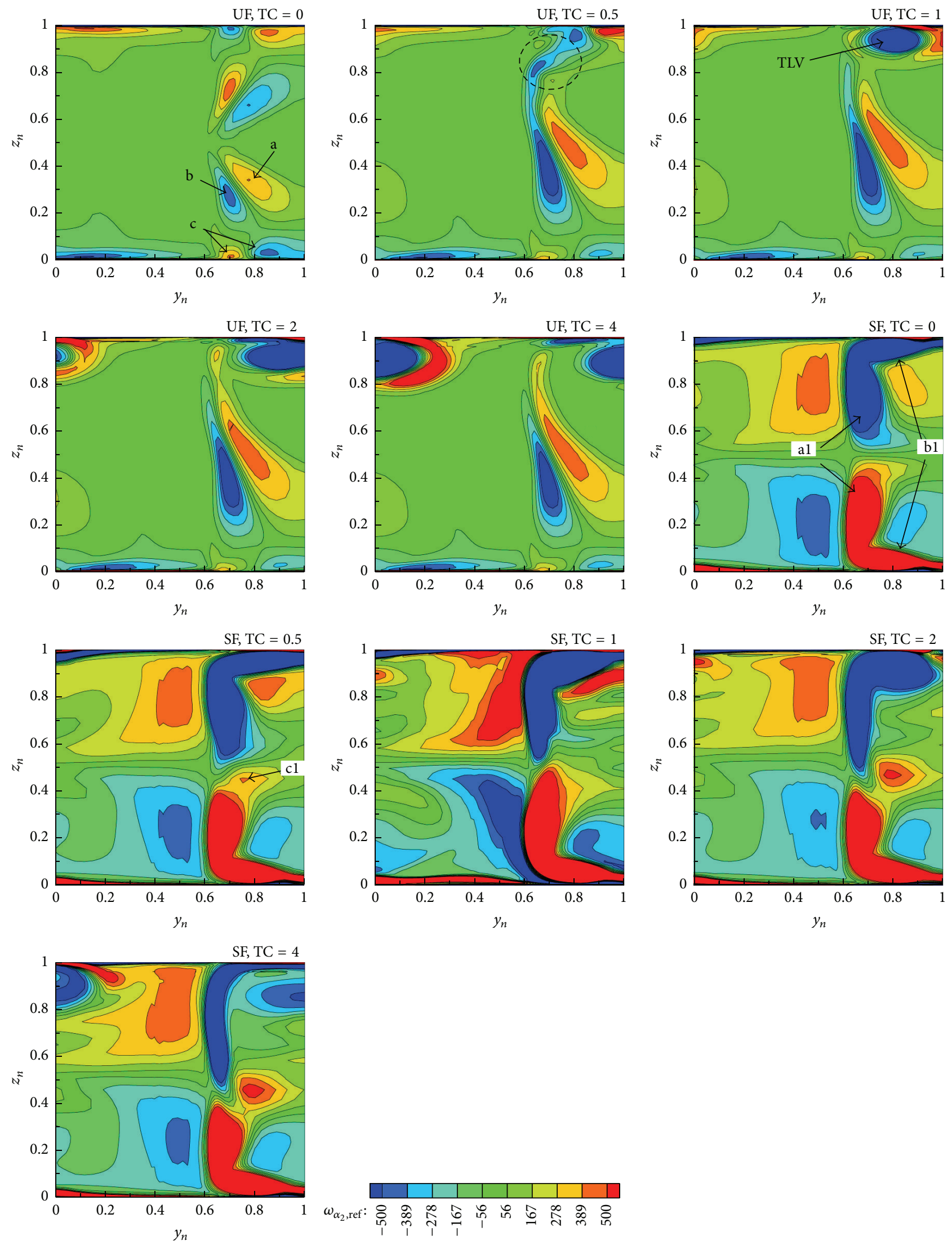

FIGURE 9: Vorticity along the reference outflow direction in the wake with UF and SF for TC $=0$ to 4 . 
depends on the extent to which it interacts with the tip leakage vortex, marked by dashed circle for the tip clearance of $0.5 \%$. The tip leakage vortex strengthens and drifts away from the suction surface in response to the tip clearance. Due to the limited interaction of the tip leakage vortex and the passage vortex at tip clearance of $2 \%$, a small induced vortex is generated.

The shear flow with a high shear rate that amplifies the end wall flow changes the appearance of the vortex structures as seen in Figure 9. Here, the vortices marked "al" are not passage vortices but appear due to the blade wake where intense vortices near the blade surface unite. The vortices marked "b1" are corner vortices. Tip leakage flux is reduced due to the reduced pressure gradient across the blade surfaces at the tip end and has little effect on the considerable end wall flows. Therefore, tip clearance less than $2 \%$ only marginally affects the passage vortex. An induced vortex marked "cl" manifests due to the interaction of vortices "al" having unequal strength for tip clearance of 0.5 . At $1 \%$, towards the tip, the tip leakage vortex and the neighbouring vortices appear to merge, resulting in increased strength. At $4 \%$ of tip clearance, the leakage vortex moves away from the suction surface of the blade and its interaction with the adjacent vortex is relieved. Further, the leakage flow near the blade trailing edge results in stretching of vortex "al" near the tip along the pitch as well as span. The higher the imbalance between vortices "al" for tip clearance greater than $2 \%$, the stronger would be the induced vortex.

5.5. Secondary Streamlines. The critical point theory is a technique used to analyze the flow structure near the wall surfaces to know the flow separation, attachment, and other $3 \mathrm{D}$ flow features. In this paper, this technique is applied to the streamlines on a plane at $x / C=0.24$ away from the trailing edge of the blade to understand the complex flow structure using streamlines only. Figure 10 shows the streamlines of the secondary vectors in the wake under different tip clearances and inflow conditions. With no tip gap, the following critical points are observed: (1) the saddle point "C1" with attachment line "A1" and separation lines "S1" and "S2"; (2) half-saddle points "C2" and "C3" corresponding to attachment lines "A2" and "A3". The separation lines "S1" and "S2" originate from "C1" that connect to nodes "N2" and "N3" and disappear. This indicates that the flow in the wake is three-dimensional with stable nodes "N2", "N3" and an unstable node "N1". The separation and attachment lines prevent the streamlines of the respective side from intersecting. After the introduction of tip clearance, an interesting change in the flow structures occurs. For $0.5 \%$ of tip clearance, the saddle point " $\mathrm{Cl}$ " shifts to the left, whereas the unstable node splits into "N1", "N3" and relocate away from midspan. The critical point "Cl" with attachment lines connects with the nodes "N1" and "N3". The separation line "S1" originates from " $\mathrm{C1}$ " and disappears into node "N4". The node "N2" transforms from attracting node to a weak attracting focus indicating the presence of tip leakage vortex. The attachment line "A1" prevents the streamlines, originating from the nodes "N2" and "N4", from crossing each other. Further increase in the tip clearance does not change the flow structure up to $50 \%$ span. For increase in the tip clearance from $1 \%$ onwards, node "N1" appears and shifts towards the right while intensifying in proportion to the tip clearance. The half saddle point "C2" also appears and shifts relative to "N1" but changes its connectivity for different tip clearance. This can be taken as an indication of the tip leakage vortex movement away from the suction surface as the tip gap increases. At $1 \%$ and $2 \%$ of tip clearance, "C2" connects "N1" and "N2" through respective attachment lines. For a large tip clearance of $4 \%$, an additional attracting focus "N5" appears. The separation line "S3" emerging from the critical point "C2" disappears into node "N4". The tip leakage vortex continuously receives energy from the tip leakage flow while travelling along the chord. This determines the strength of the tip leakage vortex. The induced end wall vortex is generated by the instability of the enwall boundary layer caused by the tip leakage vortex and the free stream flow. Now the strength of the induced end wall vortex primarily depends on the energy received from tip leakage vortex. Hence, with the increase in tip clearance, the diffusion of induced end wall vortex downstream is prolonged. Therefore, it is obvious for the secondary flow structure to undergo change in response to the influencing entities, namely, tip leakage vortex, passage vortex, and induced end wall vortex.

The inlet disturbance, in the form of a shear flow, has a tremendous effect on the secondary flow structure as seen in Figure 10. For no tip gap, two large attracting foci, "N1" and "N3", appear that are symmetrical to the midspan and indicate strong passage vortices due to the elevated end wall effect. The critical point "C1" connects to "C2" through a separating line "S1". The streamlines originating from the nodes "N1" and "N3" are prevented from crossing by the separating line "S1". The separating lines "S2" and "S3" originating from the saddle point " $\mathrm{C} 2$ " envelopes the streamlines from the attracting foci "N1" and "N3". The half-saddle points "C2" and "C3" appear at the end walls and are hardly affected by the tip clearance and the type of flow. The attachment line "A1" keeps the streamlines from nodes "N2" and "N4" separate. Compared to uniform flow case, there is a substantial increase in the strength of vortices. This shows that the secondary flow structure is sensitive to the incoming disturbance. The nature of the secondary flow structure from $50 \%$ pitch onwards is nearly unchanged up to $1 \%$ of the tip clearance, except that the node "N1" dominates over "N3". From $2 \%$ of the tip clearance onwards, node "N3" shifts towards the right as the critical point "C1" appears at the left of the midspan. Additional critical point "C4" and node "N5" appear that are connected through a separation line. The point "C4" also connects "N4" through the attachment line. Therefore, it can be concluded that the incoming disturbance has a substantial influence on the secondary flow and associated losses with it.

5.6. Tip Gap Region Coefficient of Total Pressure. The contours of the coefficient of total pressure on the suction surface of the blade of the tip gap region are shown in Figure 11. In the uniform flow case, the intensity of $C_{p_{0}}$ decreases relatively faster with tip clearance. The viscous effects that cause total pressure loss are more dominant in the near wall region for small tip clearances up to $0.5 \%$ and therefore the peaks of $C_{p_{0}}$ occur on the end wall and the blade tip. The $C_{p_{0}}$ core 

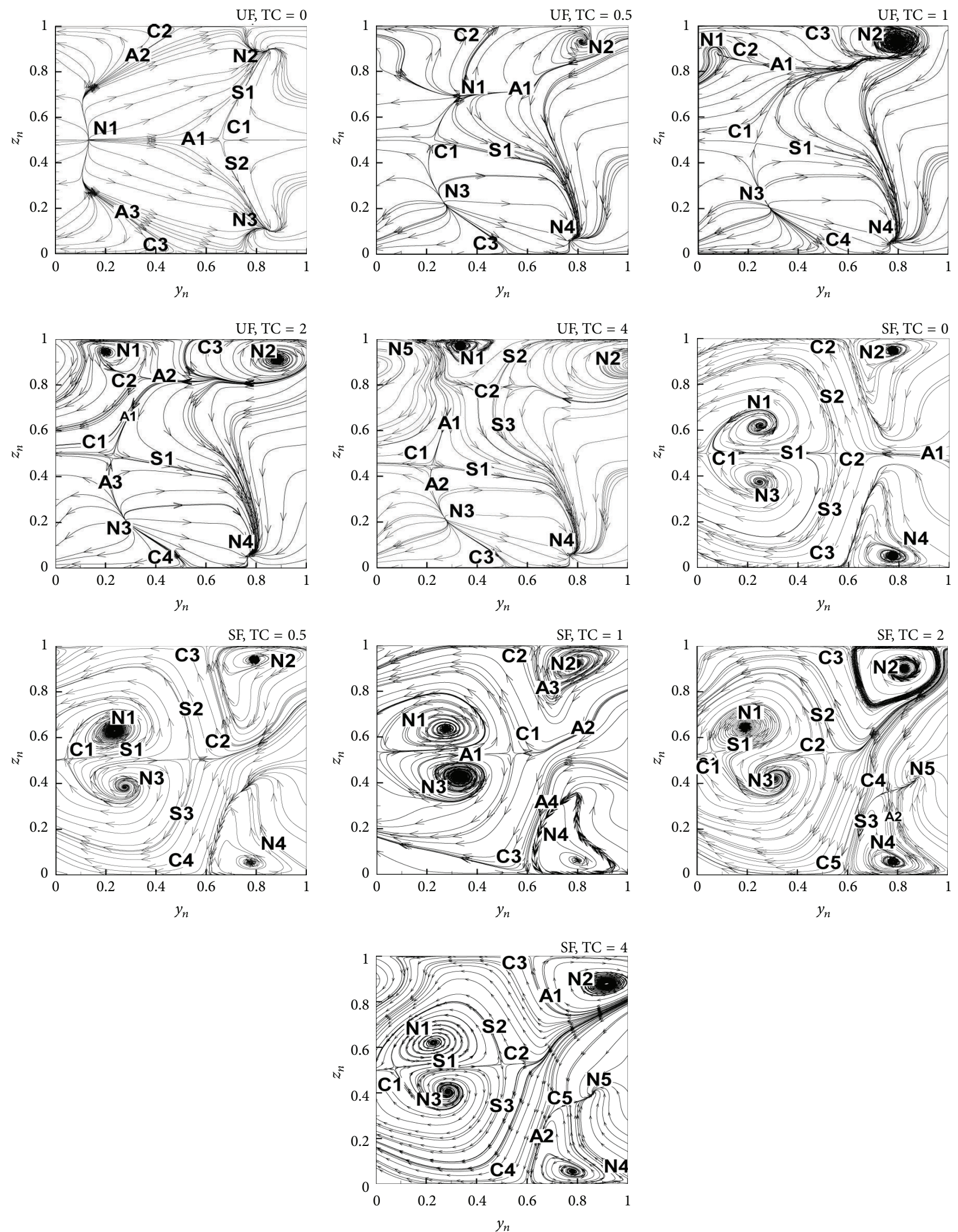

FIGURE 10: Streamline of secondary vectors in the wake along the direction of reference exit flow in the wake with UF and SF for TC $=0$ to 4 . 

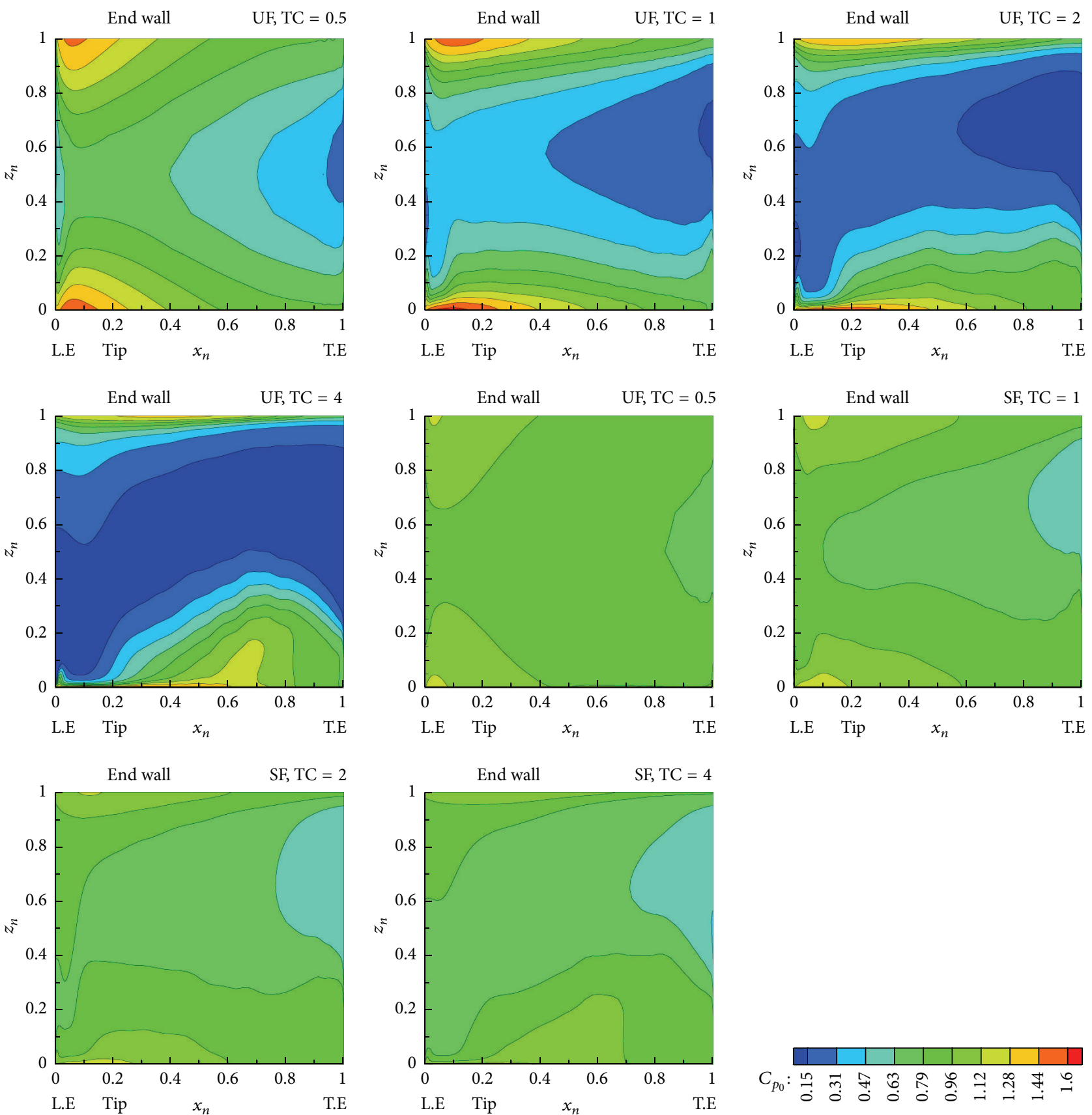

FIGURE 11: $C_{p_{0}}$ contours on the suction side of tip gap region, with UF and SF for $\mathrm{TC}=0.5$ to 4 .

on the end wall diminishes and stretches for tip clearances greater than $0.5 \%$ as the boundary layer is suppressed by the increased tip leakage flux, thereby promoting turbulence. Contrary on the tip end, the peak $C_{p_{0}}$ diminishes, and the contours are denser and shift towards the trailing edge in proportion to peak blade loading at the tip. Further, the tip leakage flux also affects the local incidence that may cause drifting of $C_{p_{0}}$ contours along the chord. The tip gap region is under the influence of viscous effects of the wall boundary layers and the inertial effect of the core flow. The influence of the inertial effect rises with tip clearance as the tip leakage flux is encouraged that energizes the boundary layers. Therefore, the overall effect is the reduction of $C_{p_{0}}$ in the tip gap region with increase in the tip clearance.

A similar trend of $C_{p_{0}}$ is observed with the shear flow, but at lower magnitudes. Since the flow near the end wall has low energy, this causes reduced momentum transfer to the blade surface. As a result, the blade loading drastically reduces in the region near the tip, which in turn leads to reduced tip leakage flux and hence the viscous effects are higher 
relative to the inertial effects. The magnitude of $C_{p_{0}}$ is therefore relatively lower and the influence of the tip clearance is gradual.

5.7. Spanwise Total Pressure Loss and Flow Deviation. The end wall loss and the deviation of the flow along the span in the wake are shown in Figure 12. With uniform flow at the inlet and no tip gap, the end wall effect extends up to $40 \%$ span as seen in Figure 12(a). As the tip gap increases, although the net loss is reduced towards the tip, the loss near the hub has proportionally increased. This is likely to cause the overall loss in the wake to be redistributed. It seems that the energy in the tip leakage flux is sufficient to influence the end wall flows for a uniform flow at the inlet. At $1 \%$ of tip clearance, the minimum end wall loss towards the tip end occurs among the cases considered and increases with tip gap, as reported by other investigators in the past. It can be inferred that up to the optimum tip gap, the tip flow counteracts the end wall flow to minimize loss. At higher tip clearances, tip flow contributes as a loss making mechanism. However, up to $60 \%$ span from the hub, the distribution of end wall loss is nearly unaffected.

From the flow deviation plots, refer to Figure 12(b), it can noted that the end wall effect causes underturning of the flow near the end wall with no tip gap, which is a feature of a secondary flow. With tip clearance, in the tip region, near the end wall, tip leakage vortex over turns the flow, which opposes the underturning caused by the secondary flow. This indicates that tip leakage flow contributes in suppressing the secondary flow to some extent. However, it causes an increase in the underturning of the flow at the hub, greater than the no tip gap configuration andremains nearly unaffected by the tip clearance. The tip clearance energizes the end wall boundary layers and the corner stall formed near the trailing edge of the suction surface. This leads to a local pressure differential along the span. In order to maintain continuity, the flow from the adjacent region moves. This leads to an increase in the under turning, near the hub.

From Figure 12(a1), it appears that the inlet shear flow has resulted in a considerable rise in the end wall loss and the tip leakage flow hardly affects the distribution of the end wall loss along the span. Therefore, the end wall loss along the span is nearly invariant, within a small tolerance band, with tip clearance. The tip leakage vortex is able to influence the exit flow angle to some degree as depicted in Figure 12(b1). Thus, it can be concluded that the inlet shear flow with higher shear rate promotes the end wall effect and the corresponding secondary flow to such a magnitude that renders the tip leakage flow less influential.

5.8. Overall Outcome on the Tip Gap Region and the Wake Region. The fine variations of interested parameters were detailed in previous sections and it may be useful to know gross effects in terms of tip leakage flux and associated power loss, static pressure rise, and overall loss in wake of these regions.

5.8.1. Tip Gap Region. The tip leakage flux depends on the effective flow area and the pressure gradient across the surfaces of the blade. For a small tip clearance of $0.5 \%$ with uniform flow, refer to Figures 13(a)-13(d), as the boundary layers would be thicker relative to the span of the tip gap, viscous effects dominate the inertia of the tip leakage flow. Therefore, the mean velocity, the corresponding flux, and the mean kinetic energy are relatively smaller in magnitude. With increase in the tip clearance the effective area and the leakage velocity also increase leading to proportionate increase in the flux and the kinetic energy. The energy associated with the leakage flow is a direct loss and hence the corresponding kinetic energy is a loss. As seen in Figure $13(\mathrm{~d}), C_{p_{0}}$ shows the opposite trend with tip clearance. This is not a surprise, as it does not represent a loss parameter like in the wake. With increase in tip clearance, the dynamic head rises as a square of the mean velocity and hence the total pressure in the tip gap region. This results in the reduction of the total pressure loss coefficient. Then some function of $\left(1-C_{p_{0}}\right)$ may represent a loss parameter for the tip gap region corresponding to the kinetic energy loss associated with the leakage flux.

The flow near the end wall region in a shear flow has lower energy and hence reduced momentum transfer to the blade surfaces. Thereby, the resulting pressure gradient across the surfaces of the blade reduces considerably. This suppresses the leakage flow and the associated kinetic energy loss. Thus, the trend is similar to the uniform flow case but at lower magnitudes except $C_{p_{0}}$ due to lower total head near the end wall region.

5.8.2. Wake. The tip leakage vortex diffuses out as it travels downstream while interacting with mainstream flow, wall boundary layers, and the secondary flow. Therefore, in the wake, $C_{p_{0}}$ has changed marginally with tip clearance, as seen in Figure 13(a1). For shear flow, the values are slightly higher as the end wall effect is promoted, the trend being the same. The loss in terms of mean kinetic energy of the secondary flow, refer to Figure 13(b1), is almost doubled with shear inflow. This can be attributed to the rise in the pressure gradient across the flow passage. Similarly, the mass averaged exit flow angle is higher with shear flow and nearly unchanged with tip clearance, as seen in Figure 13(c1). On the contrary, with uniform flow, the exit flow angle first reduces rapidly up to $1 \%$ of the tip clearance and then rises gradually. This can be attributed to the ability of the tip leakage vortex to counteract the underturning effect of the secondary flow near the tip region and is optimum at $1 \%$ tip clearance. Further increase in the tip clearance strengthens and moves the tip leakage vortex towards the pressure surface of the adjacent blade and the interaction with adjacent vortex is relieved. Therefore, the overall effect is the increase in the exit flow angle. The static pressure rise in the wake is optimum between $1 \%$ and $2 \%$ of tip clearance and thereafter drops, for uniform flow, as seen in Figure 13(d1). The tip leakage vortex interacts with the free stream flow and the stall region near the trailing edge, thereby energizing it. This improves the diffusion ability of the flow passage and results in rise in the $C_{p}$. In case of shear flow, it is nearly constant as the stall near the trailing edge due to substantial end wall effects limits the effective area for flow diffusion and the tip clearance up to $4 \%$ is ineffective to counter it. 

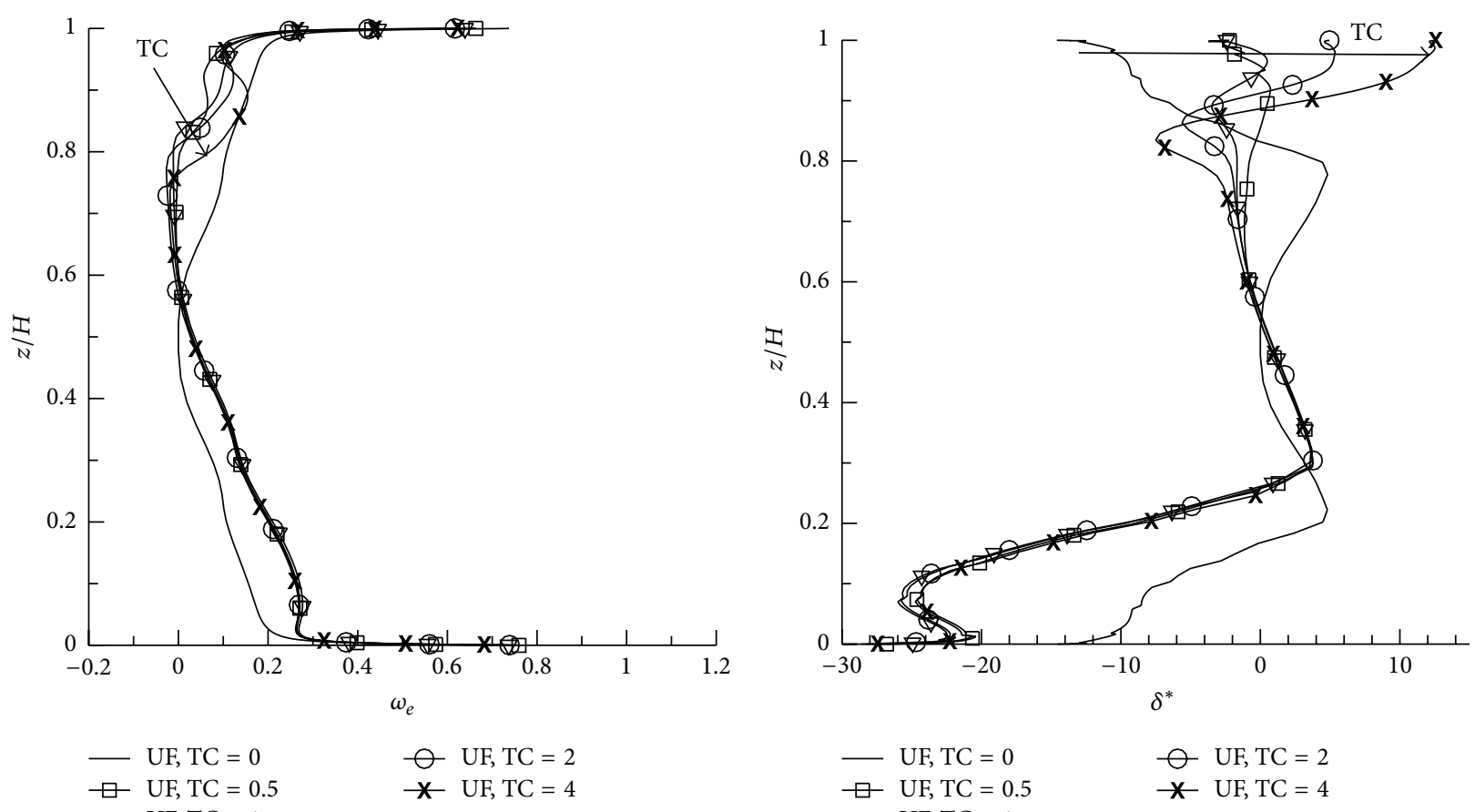

(a)

(b)
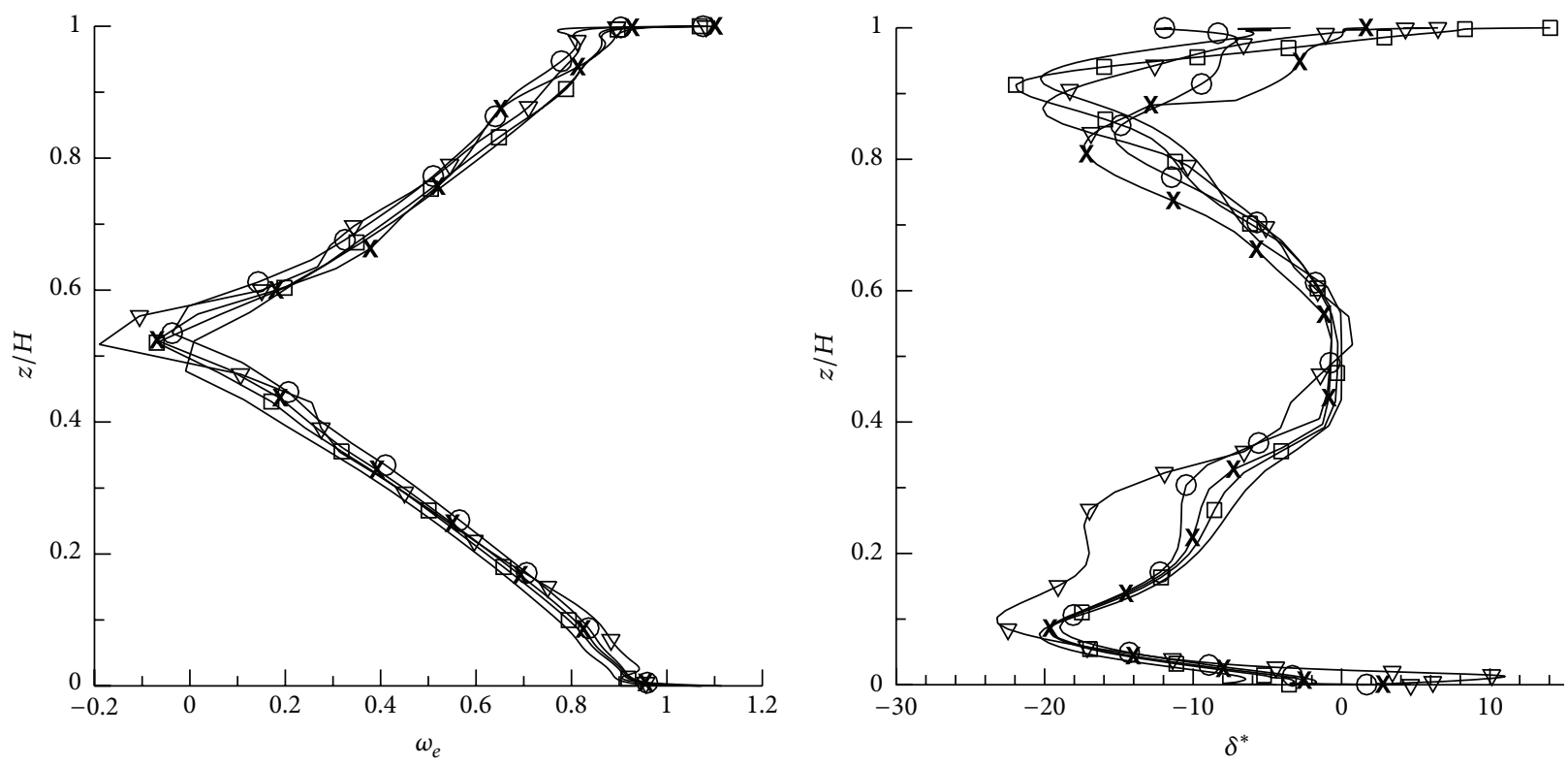

$$
\begin{aligned}
& \square \text { SF, TC }=0 \\
& \square \text { SF, TC }=0.5 \\
& \nabla \quad \text { SF, TC }=1
\end{aligned}
$$$$
\oslash \mathrm{SF}, \mathrm{TC}=2
$$$$
\text { - } \mathrm{SF}, \mathrm{TC}=4
$$

$$
\begin{aligned}
& -\mathrm{SF}, \mathrm{TC}=0 \\
& \square \quad \mathrm{SF}, \mathrm{TC}=0.5 \\
& \nabla \quad \mathrm{SF}, \mathrm{TC}=1
\end{aligned}
$$

$\vartheta \mathrm{SF}, \mathrm{TC}=2$

- $\mathrm{SF}, \mathrm{TC}=4$

(b1)

FIGURE 12: End wall loss and flow deviation with reference to exit flow angle along the span in the wake with UF and SF for TC $=0.5$ to 4 .

5.9. Tip Leakage Path. Tip leakage vortex behaves differently under the variation of the tip clearance and the type of inlet flow. This has an impact on the total pressure loss in the wake. To understand the loss making mechanism, the path of the vortex cores downstream has to be traced. There are different methods to locate the centre of the vortex core like static pressure, vorticity, and so forth. In this paper, the total pressure loss is employed, which is scaled proportionally to scrutinize the fine details of the flow interaction and is shown in Figure 14. The tip leakage vortex (TLV) drifts away from the suction surface while moving downstream with increase in the tip clearance. The momentum transfer to the tip leakage 


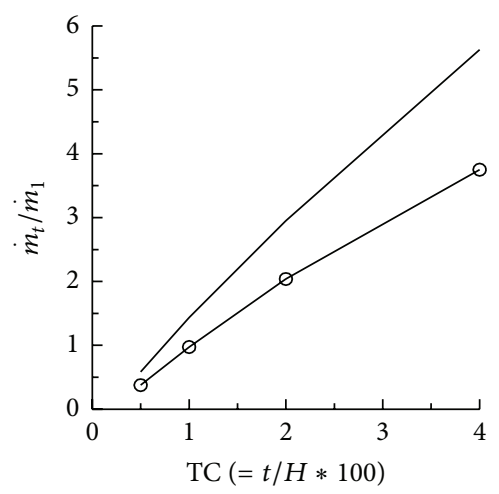

(a)

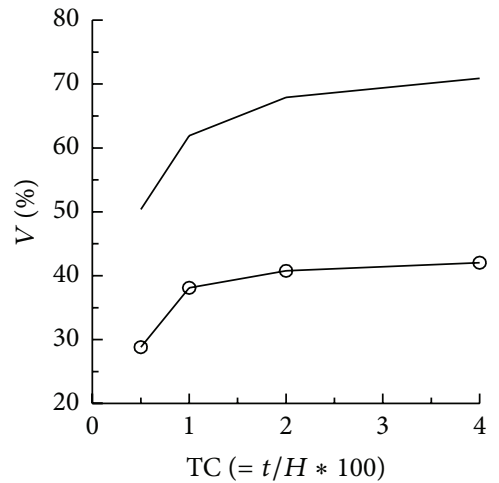

(b)

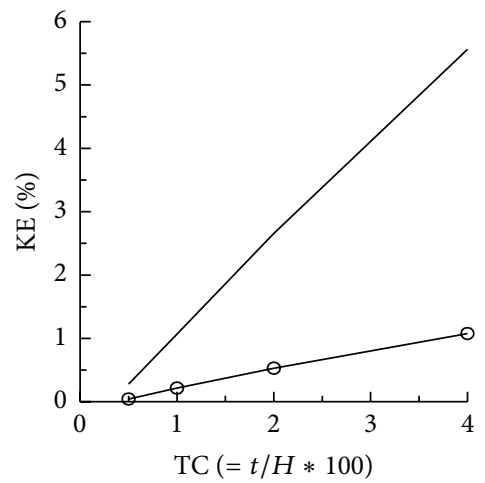

(c)

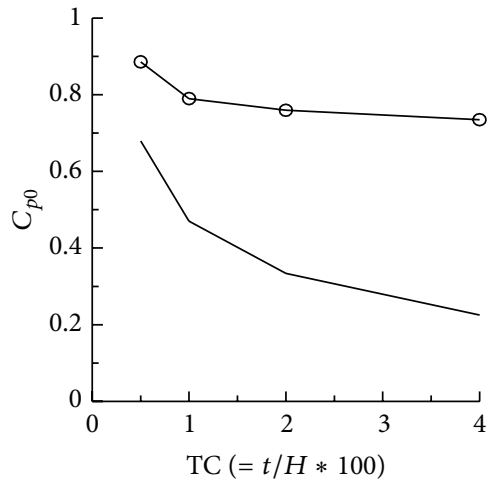

- UF

- SF

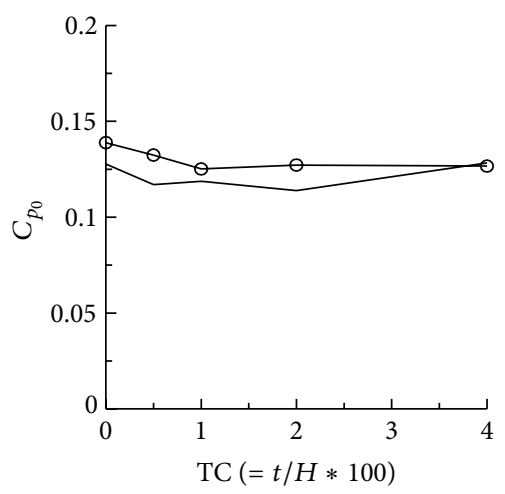

(a1)

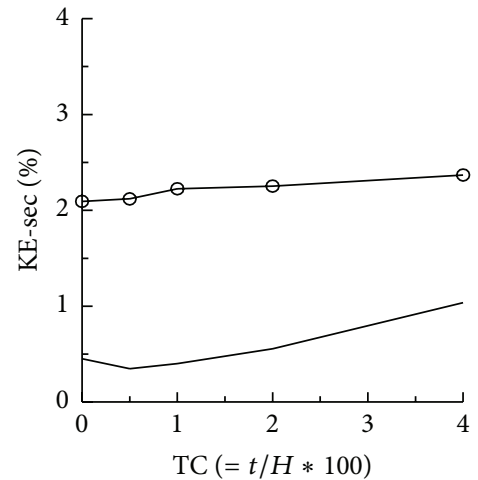

(b1)

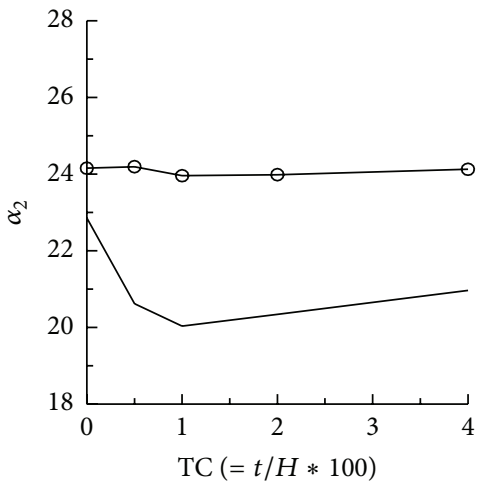

(c1)

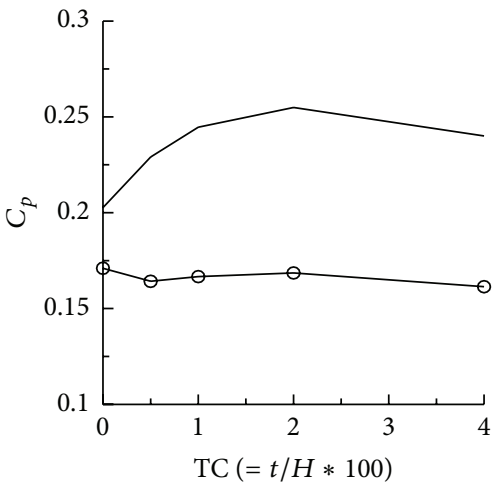$$
-\mathrm{UF}
$$

(d)

(d1)

FIGURE 13: Overall effects in the tip gap region and wake, with reference to TC. 

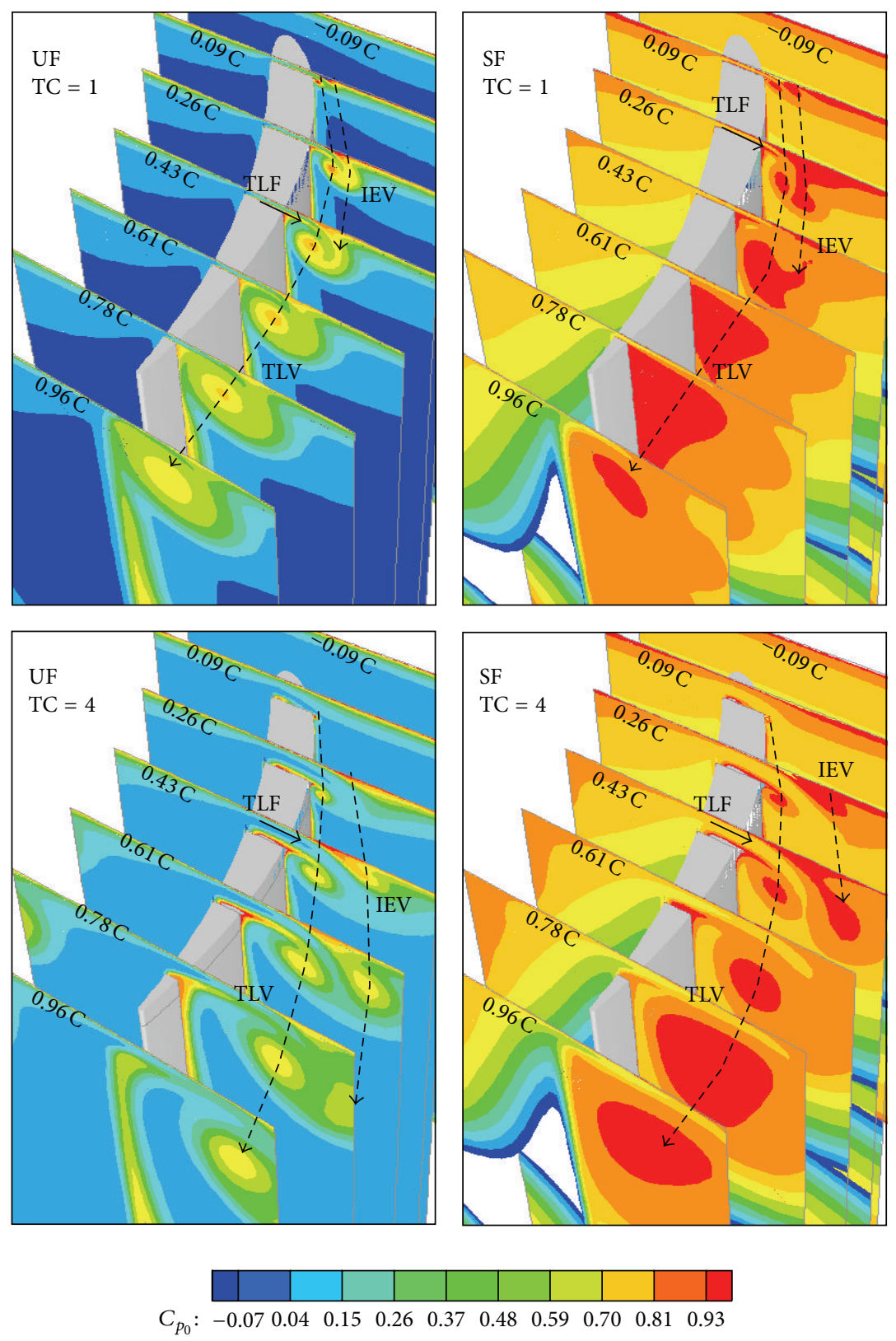

FIGURE 14: Interaction of TLV (tip leakage vortex), IEV (induced end wall vortex), and TLF (tip leakage flow) with UF and SF at $1 \%$ and $4 \%$ tip clearance. Total pressure loss contours are used.

vortex in the lateral direction by the tip leakage flow occurring along the chord is the primary cause of this drifting. The secondary cause is the interaction of TLV with end wall vortex (IEV) which is induced by tip leakage flow and TLV by forcing the end wall boundary layers to instability. The strength of the vortex depends on its rate of diffusion, governed by the energy transfers with the adjacent regions, as it travels downstream. Therefore, the amount of drifting of TLV away from suction surface in $4 \%$ tip clearance is more compared to $1 \%$, as the end wall vortex is stronger and travels far downstream relatively, besides increased tip leakage flux. But in the case of shear flow, the drifting is less compared to the uniform flow as the induced end wall vortex is short lived as tip leakage flux is drastically reduced due to lower pressure gradient across the blade surface that drives it. The tip leakage vortex is pushed towards the suction surface by the prevailing secondary flow from $60 \% \mathrm{C}$ onwards. Since, the secondary flow is enhanced due to the inlet shear flow, the drifting of TLV is suppressed by higher magnitude compared to the uniform flow. Therefore, the resulting path of tip leakage vortex downstream depends on the strength of tip leakage flow, secondary flow, and induced end wall vortex flow.

\section{Conclusions}

A numerical study was conducted to investigate the flow dynamics near the tip clearance region to understand the role of tip clearance in presence of shear flow. CFD proved to 
be a valuable tool to probe into fine details, which may be difficult or impossible by conventional instrumentation. The conclusions drawn are as follows.

(i) It is possible to produce a strong shear flow with shear rate of 1.33 using strips of screen of different solidity. Shear profile is nearly stable downstream until $15.13 \mathrm{~h}$ and the decay rate is gradual.

(ii) Tip clearance promotes the favorable local incidence and improves the blade loading near the tip. It also has the tendency to shift the peak loading point at the tip downstream along the chord, which limits the extent of flow separation near the tip.

(iii) Tip clearance shifts the centre of pressure towards the tip side for the inlet uniform flow and is marginal in the case of shear flow.

(iv) The tip clearance with uniform inflow considerably reduces the total pressure loss in the wake towards the tip. However, it is nearly ineffective with shear flow, where end wall effects are considerably large for the tip leakage flow to influence.

(v) The shear flow has substantial effect on the structure of the secondary flow.

(vi) The variation of tip clearance has no effect on the distribution of the end wall loss and the deviation angle along the span up to $60 \%$ from end wall, whereas with shear flow it has some effect.

(vii) Tighter the tip clearances lower would be the tip leakage loss in terms of the associated kinetic energy. The shear flow further reduces them considerably.

(viii) The kinetic energy associated with the secondary flow in shear is nearly twice the uniform flow case. This can be attributed to the elevated transverse pressure gradient of the blade passage.

\section{Nomenclature}

C: $\quad$ Blade chord, $\mathrm{m}$

$C_{p}: \quad$ Static pressure coefficient, $=\left(P_{2}-P_{1}\right) /$

$\left(1 / 2^{*} \rho^{*} U^{2}\right)$

$C_{p_{0}}: \quad$ Total pressure coefficient, $=\left(P_{02}-P_{01}\right) /$

$\left(1 / 2 * \rho^{*} U^{2}\right)$

$C_{p_{0}, \text { ref }}$ : Total pressure coefficient in the wake at midspan for $t=0, \mathrm{~Pa}$

$H$ : $\quad$ Blade span, $\mathrm{m}$

$h$ : Semiblade span/height of shear generator, $\mathrm{m},=H / 2$

$i: \quad$ Incidence angle, deg.

IEV: Induced end wall vortex

KE: $\quad$ Kinetic energy

KE-sec: Kinetic energy of secondary flow

$K_{0}$ : $\quad$ Grid resistance

P.S: $\quad$ Pressure surface of the blade

\begin{tabular}{|c|c|}
\hline$P_{1}, P_{2}:$ & $\begin{array}{l}\text { Upstream and downstream static pressure, } \\
\text { respectively, } \mathrm{Pa}\end{array}$ \\
\hline$P_{01}, P_{02}:$ & $\begin{array}{l}\text { Upstream and downstream stagnation } \\
\text { pressure, respectively, } \mathrm{Pa}\end{array}$ \\
\hline Re: & Reynolds number based on chord length \\
\hline$S:$ & Pitch of blade, $\mathrm{m}$ \\
\hline$s:$ & $\begin{array}{l}\text { Pitch/spacing between wires of square } \\
\text { mesh, m }\end{array}$ \\
\hline SF: & Shear flow \\
\hline S.S: & Suction surface of the blade \\
\hline SC1, SC2, SC3: & Screen strips of different solidities \\
\hline$t:$ & Tip gap, m \\
\hline TC: & Tip clearance ratio, $t / H$ \\
\hline TLV: & Tip leakage vortex \\
\hline$U:$ & Mean inlet velocity, $\mathrm{m} / \mathrm{s}$ \\
\hline UF: & Uniform flow \\
\hline$u, v, w:$ & Velocity components, $\mathrm{m} / \mathrm{s}$ \\
\hline$x, y, z:$ & Cartesian coordinates \\
\hline$x_{n}, y_{n}, z_{n}:$ & $\begin{array}{l}\text { Normalized coordinates with respect to } C, S \\
\text { and corresponding span }\end{array}$ \\
\hline$\alpha_{2}:$ & Exit flow angle, deg. \\
\hline$\alpha_{2, \mathrm{ref}}:$ & $\begin{array}{l}\text { Exit flow angle in the wake at midspan for } \\
t=0, \text { deg. }\end{array}$ \\
\hline$\lambda:$ & Velocity gradient, $1 / \mathrm{s},=\partial U / \partial z$ \\
\hline$\delta^{*}:$ & $\begin{array}{l}\text { Deviation from the reference exit flow } \\
\text { angle, }\left(\alpha_{2}-\alpha_{2 \text {,ref }}\right) \text {, deg. }\end{array}$ \\
\hline$\lambda h / U:$ & Shear parameter \\
\hline$\sigma:$ & Solidity of wire mesh \\
\hline$\omega_{e}:$ & End wall loss, $\left(C_{p_{0}}-C_{p_{0}, \text { ref }}\right)$ \\
\hline$\omega_{\alpha 2, \text { ref: }}:$ & Vorticity along $\alpha_{2, \mathrm{ref}}, 1 / \mathrm{s}$. \\
\hline
\end{tabular}

\section{Conflict of Interests}

This is to state that there is no potential and/or relevant financial or other conflict of interests that might affect the publication of the results contained in this paper.

\section{References}

[1] D. A. Rains, "Tip clearance flows in axial flow compressors and pumps," Tech. Rep. no. 5, California Institute of Technology, Hydrodynamics and Mechanical Engineering Laboratories, Pasadena, Calif, USA, 1954.

[2] G. T. Chen, E. M. Greitzer, C. S. Tan, and F. E. Marble, "Similarity analysis of compressor tip clearance flow structure," Journal of Turbomachinery, vol. 113, no. 2, pp. 260-269, 1991.

[3] J. A. Storer and N. A. Cumpsty, "Tip leakage flow in axial compressors," Journal of Turbomachinery, vol. 113, no. 2, pp. 252-259, 1991.

[4] S. A. Khalid, A. S. Khalsa, I. A. Waitz et al., "Endwall blockage in axial compressors," Journal of Turbomachinery, vol. 121, no. 3, pp. 499-509, 1999.

[5] J. D. Denton, "Loss mechanisms in turbomachines," Journal of Turbomachinery, vol. 115, no. 4, pp. 621-656, 1993.

[6] F. Soranna, Y.-C. Chow, O. Uzol, and J. Katz, "Flow structure and turbulence in the tip region of a turbomachine rotor blade," in Proceedings of the ASME Turbo EXPO : Power for Land, Sea and Air, GT2007-27590, pp. 1687-1699, Montreal, Canada, May 2007. 
[7] Z. Zhibo, Y. Xianjun, and L. Baojie, "Characteristics of the tip leakage vortex in a low-speed axial compressor with different rotor tip gaps," in Proceedings of the ASME Turbo EXPO, GT2012-69148, Copenhagen, Denmark, 2012.

[8] R. Williams, D. Gregory-Smith, L. He, and G. Ingram, "Experiments and computations on large tip clearance effects in a linear cascade," Journal of Turbomachinery, vol. 132, no. 2, pp. 1-10, 2010.

[9] D. You, M. Wang, P. Moin, and R. Mittal, "Effects of tip-gap size on the tip-leakage flow in a turbomachinery cascade," Physics of Fluids, vol. 18, no. 10, Article ID 105102, 14 pages, 2006.

[10] B. Roy and D. Bhatia, "Aerodynamics of tip leakage flows in a high hub-tip ratio low speed axial flow compressor rotor," in Proceedings of the 37th National \& 4th International Conference on Fluid Mechanics and Fluid Power, IIT Madras, Chennai, India, 2010.

[11] A. Fischer, L. Buttner, J. Czarske, M. Gottschall, R. Mailach, and K. Vogeler, "Investigation of the tip clearance flow in a compressor cascade using a novel laser measurement technique with high temporal resolution," in Proceedings of the ASME Turbo EXPO, GT2011-45176, British Columbia, Canada, 2011.

[12] R. E. Peacock, "A review of turbomachinery tip gap effects. Part 2: rotating machinery," International Journal of Heat and Fluid Flow, vol. 4, no. 1, pp. 3-16, 1983.

[13] R. Ma and W. J. Devenport, "Tip gap effects on the unsteady behavior of a tip leakage vortex," Journal of the American Institute of Aeronautics and Astronautics, vol. 45, no. 7, pp. 1713-1724, 2007.

[14] B. Lakshminarayana, M. Zaccaria, and B. Marathe, "The structure of tip clearance flow in axial flow compressors," Journal of Turbomachinery, vol. 117, no. 3, pp. 336-347, 1995.

[15] P. R. Owen and H. K. Zienkiewicz, "The production of uniform shear flow in a wind tunnel," Journal of Fluid Mechancis, vol. 2, no. 06 , pp. 521-531, 1957.

[16] J. L. Livesey and J. T. Turner, "The generation of symmetrical duct velocity profiles of high uniform shear," Journal of Fluid Mechancis, vol. 20, no. 2, pp. 201-208, 1964.

[17] A. Lloyd, "The generation of shear flow in a wind tunnel," Quarterly Journal of the Royal Meteorological Society, vol. 93, no. 395, pp. 79-96, 1967.

[18] J. W. Elder, "Steady flow through non-uniform gauzes of arbitrary shape," Journal of Fluid Mechanci, vol. 5, no. 03, pp. 355$368,1959$.

[19] G. V. Davis, "The flow of air through wire screens," in Proceedings of the 1st Australasian Conference on Hydraulics and Fluid Mechanics, pp. 191-212, University of Western Australia, December, 1962.

[20] J. L. Levesey and E. M. Laws, "Flow through non-uniform gauze screens," Journal of Fluid Mechanics, vol. 59, no. 4, pp. 737-743, 1973.

[21] S. Tavourlaris and U. Karnik, "Further experiments on the evolution of turbulent stresses and scales in uniformly sheared turbulence," Journal of Fluid Mechanics, vol. 204, pp. 457-478, 1989.

[22] D. R. Kotansky, "The use of honeycomb for shear flow generation," Journal of the American Institute of Aeronautics and Astronautics, vol. 4, no. 8, pp. 1490-1491, 1966.

[23] W. R. Hawthorne and W. D. Armstrong, "Shear Flow through a Cascade," Aeronautical Quarterly, vol. 7, pp. 247-274, 1956. 

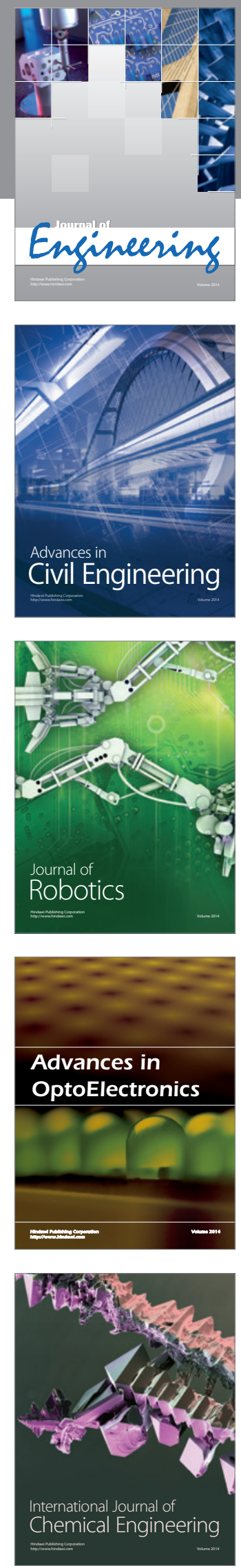

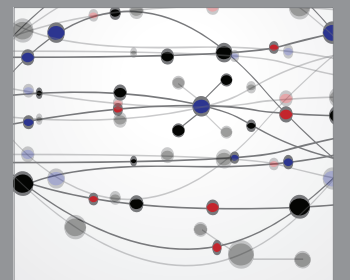

The Scientific World Journal
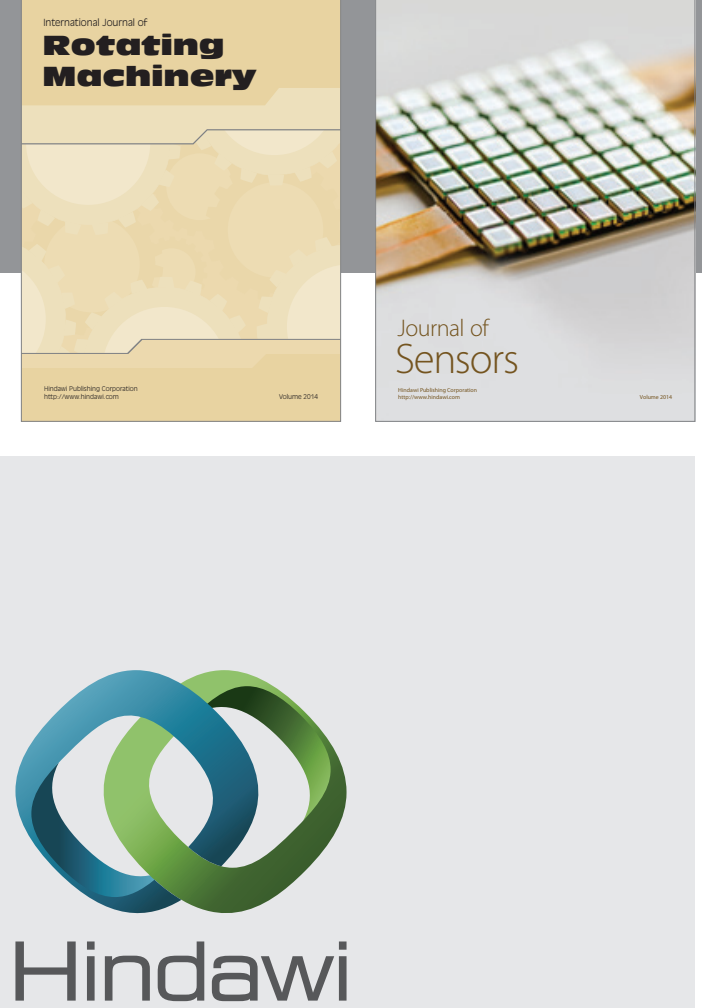

Submit your manuscripts at http://www.hindawi.com
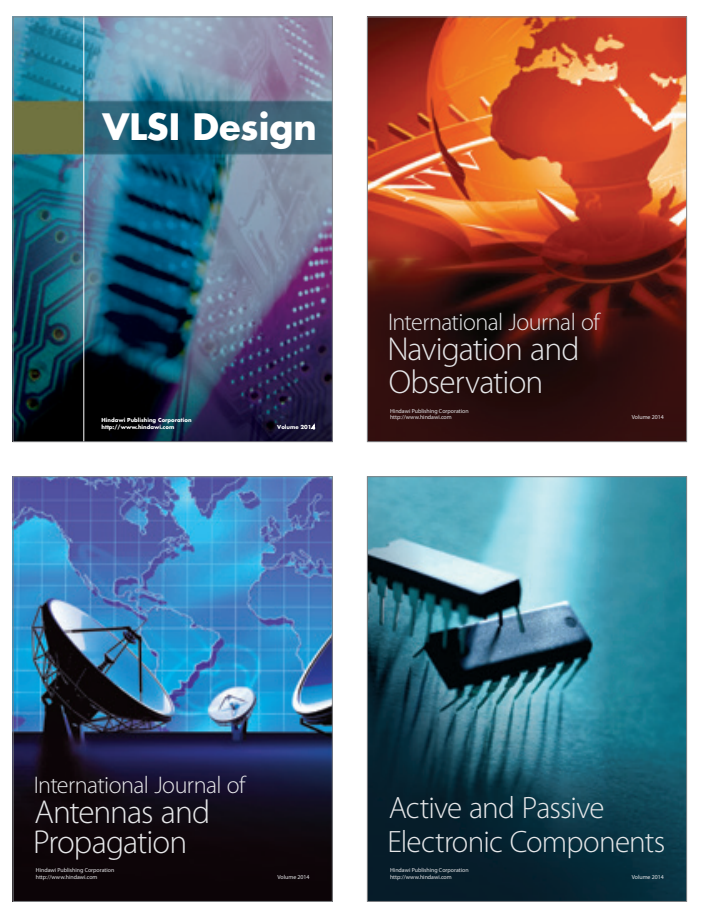
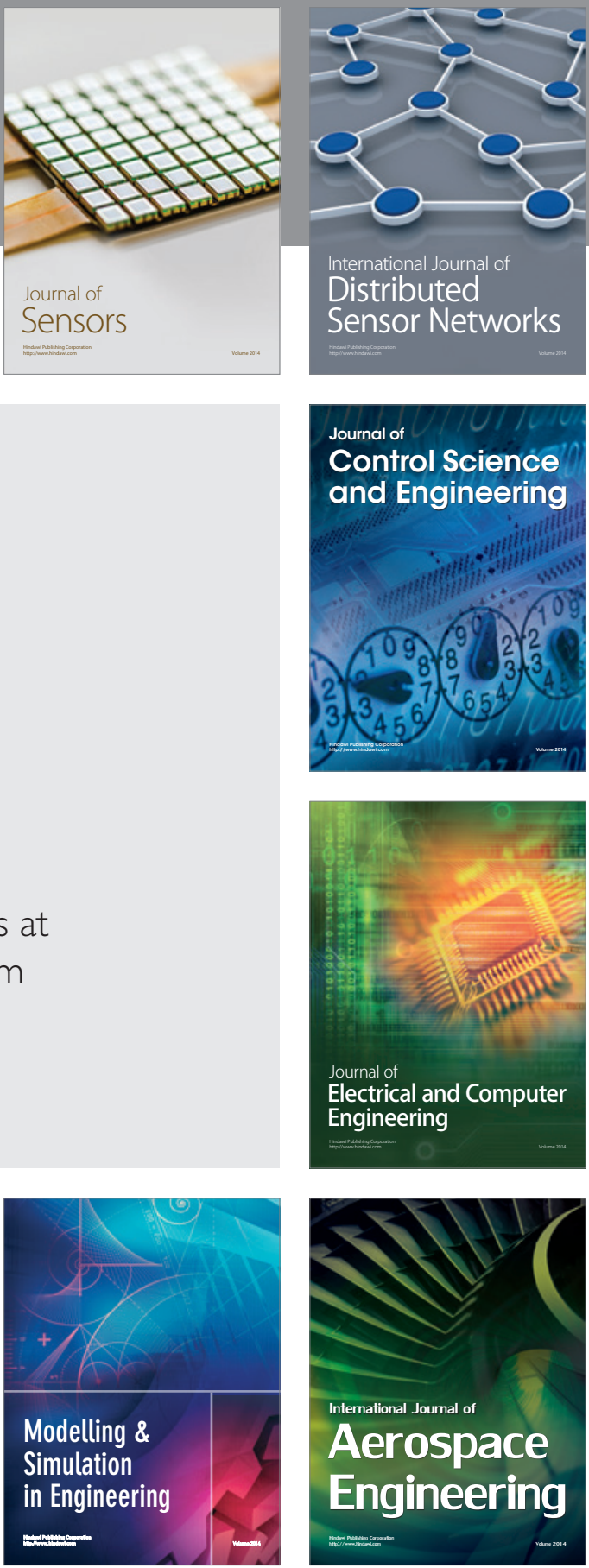

Journal of

Control Science

and Engineering
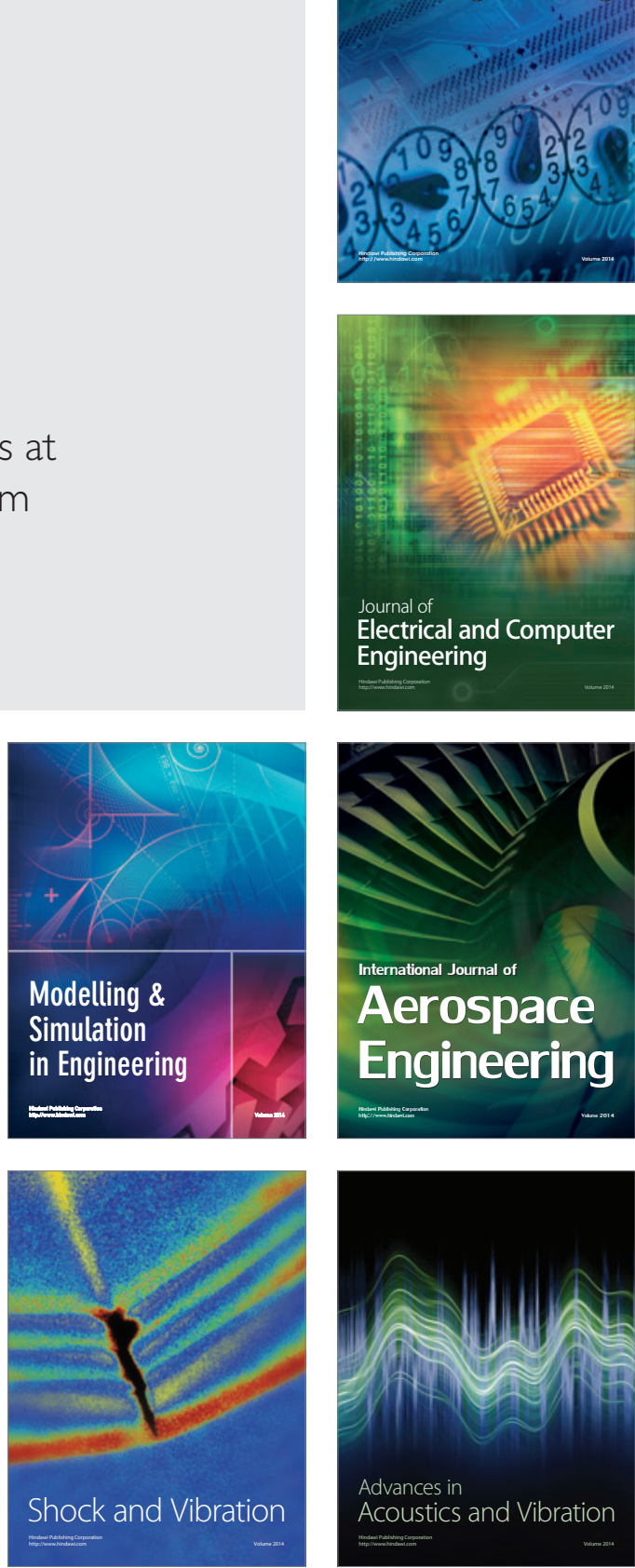